\section{Resorption: part 1. Pathology, classification and aetiology}

\author{
J. Darcey ${ }^{* 1}$ and A. Qualtrough ${ }^{2}$ \\ VERIFIABLE CPD PAPER
}
IN BRIEF
- Explains the pathological process involved in dental resorption.
- Discusses the classification of differing resorptive lesions.
- Highlights the most common stimuli to resorption.

This paper will explore the pathological process involved in dental resorption as well as its classifications and aetiology.

The second subsequent paper will look at its diagnosis and management.

\section{INTRODUCTION}

Root resorption is the progressive loss of dentine and cementum through the continued action of osteoclastic cells. ${ }^{1}$ In the primary/mixed dentition this is a normal physiological process resulting in exfoliation of deciduous teeth but in the adult dentition is largely pathological. Resorption can occur both internally and externally and is known to be initiated and maintained by many factors but pulpal necrosis, trauma, periodontal treatment, orthodontic treatment and tooth whitening agents are the most commonly described stimulants. ${ }^{2}$ Irrespective of the initial cause the process is largely inflammatory in origin. ${ }^{3}$

Without intervention premature loss of the affected tooth may occur. Successful management is dependent upon a thorough understanding of the diagnosis. External surface resorption is often an incidental finding, self limiting and best simply monitored. External inflammatory root resorption is optimally managed with endodontic therapy but may also require surgical exposure and direct restoration of the lesion. If external replacement resorption (ankylosis) is suspected then decoronation or close monitoring are recommended.

'Speciality Trainee and Honorary Lecturer in Restorative Dentistry, ${ }^{2}$ Senior Lecturer/Honorary Consultant

in Restorative Dentistry, University Dental Hospital of Manchester, Higher Cambridge Street, Manchester, M15 6FH

${ }^{*}$ Correspondence to: James Darcey

Email: jimdarcey@hotmail.com

\section{Refereed Paper}

Accepted 26 February 2013

DOI: 10.1038/sj.bdj.2013.431

${ }^{\circledR}$ British Dental Journal 2013; 214: 439-451
In rare circumstances elective extraction may be required but clinicians should be aware of the potential difficulties of removing ankylosed teeth. Internal inflammatory resorption requires root canal treatment with care to ensure good chemo-mechanical disinfection and adequate extension and compaction of the root filling into the cleaned resorptive cavity. ${ }^{4}$

The aim of this series of two papers is to review the literature related to the aetiology, pathology, diagnosis and management of root resorption and to suggest simple protocols for treatment.

\section{HISTORY}

Although considered to be a recently recognised phenomenon, a process which could be attributed to resorption was described in what is thought to be the first book devoted to dentistry. ${ }^{5}$ In 1806 Joseph Fox likened the process to tumours of the bone; spina ventosa. ${ }^{6}$ Tomes termed the process absorption in $1859 ;^{7}$ 'while the crown of a tooth is perfectly sound, the root is attacked by absorption... In neither patient was there any indication of the presence of disease, either in the gum or in the alveolar process.' He drew attention to two types of resorption, the first being when part or the whole of the root is resorbed without reference to another tooth and the second in which a malpositioned tooth overlies the root of an erupted tooth leading to the destruction of root surface. Tomes described impacted canines and wisdom teeth as being the prime protagonists. ${ }^{7}$ In 1901 Miller described irregularly shaped cavities and hypothesised that their cause was a combination of resorption and pulpal infection. ${ }^{8}$ In 1920 Mummery described pink areas on teeth: it is likely that today these would be diagnosed as having internal resorptive lesions. ${ }^{9}$ These classical texts are predominantly descriptive with only few suggestions related to aetiology. Thus the process of resorption despite having been recognised for centuries has been poorly understood and managed until relatively recently.

\section{PATHOPHYSIOLOGY}

The resorptive process has been linked to the osteoclast. ${ }^{10}$ Osteoclasts are large multinucleate cells found within lacunae (Howship's) or crypts on hard tissue surfaces. They are highly motile and have prominent pseudopodia. They are distinguished from other multinucleate cells in that the surface in contact with the bone/ dentine has a highly ruffled border. This was first described in 1956. ${ }^{11}$ Within the ruffled border intracellular vesicles fuse with the cell membrane and consequently release hydrogen ions and proteolytic enzymes into a resorptive compartment between cell and tissue surface. ${ }^{12}$ This environment is highly acidic and as a result there is dissolution of calcified hard tissue. The ruffled zone is effectively sealed to the bone by integrins. Integrins are heterodimeric receptors involved in cellular processes such as migration, attachment, proliferation, differentiation and cell survival. ${ }^{13}$ Integrins in the ruffled border of the osteoclasts interact with ligands, coupling the cell to the extracellular matrix of the root/bone thus isolating the resorptive area (Fig. 1). Integrins are also essential in cell activity and play a role in the communication of information 
to the cell about its surroundings and functional requirements. ${ }^{14}$ The cytoplasm of the cell contains an array of organelles that are intimately associated with an active digestive role including: extensive endoplasmic reticulum, golgi aparatus, ribosomes and vast assemblies of intracellular vesicles that migrate towards the ruffled zone. Odontoclasts and osteoclasts have similar modes of action but act at different sites. In this paper the term osteoclast will be used. ${ }^{15}$

Osteoclasts are the main driver of resorption and can break down bone, cartilage and most notably in the context of this paper, dentine. ${ }^{16}$ The precise origin and stimulation of the osteoclast has not yet been conclusively proven. Multiple theories have been postulated but chemical signals: osteoclast differentiation factor/osteoprotegrin ligand/receptor activator of nuclear factor $\kappa$-B ligand (ODF/OPGL/RANKL), are now known to control their formation. ${ }^{17}$ These are members of the tumour necrosis factor cytokine family. ${ }^{18}$ RANKL is liberated from osteoblasts and stromal cells. RANKL receptors are found on the surface of monocytes and macrophages and release is thought to stimulate these macrophages and mononuclear cells to fuse and become osteoclasts. RANKL is essential in both the development and function of osteoclasts. ${ }^{18}$ The osteoprotegrin/osteoclast inhibitory factor (OPG/OCIF) is a glyco-protein and is also a member of the tumour necrosis factor receptor super family. This too is secreted by osteoblasts and stromal cells but inhibits RANKL, thus inhibiting osteoclastic activity. ${ }^{19}$ RANKL expression can be stimulated by parathyroid hormone, vitamin D3 and interleukin-1B. ${ }^{20,21}$ This latter chemical mediator is integral to the inflammatory processes. Indeed, interleukin 1B has been shown to be intimately related to resorptive processes of dental hard tissues associated with both periapical and periodontal disease. ${ }^{22,23}$ It may be that patients with variations in the interleukin 1B allele have a genetic predisposition to a resorptive tendency. ${ }^{24}$

A further significant stimulant to the resorptive process is associated with the presence of bacteria. Complement proteins, bacterial toxins and antibodies from B lymphocytes attract these leukocytes. Though not all chemical mediators of inflammation found in pulpal and periapical tissue are associated with

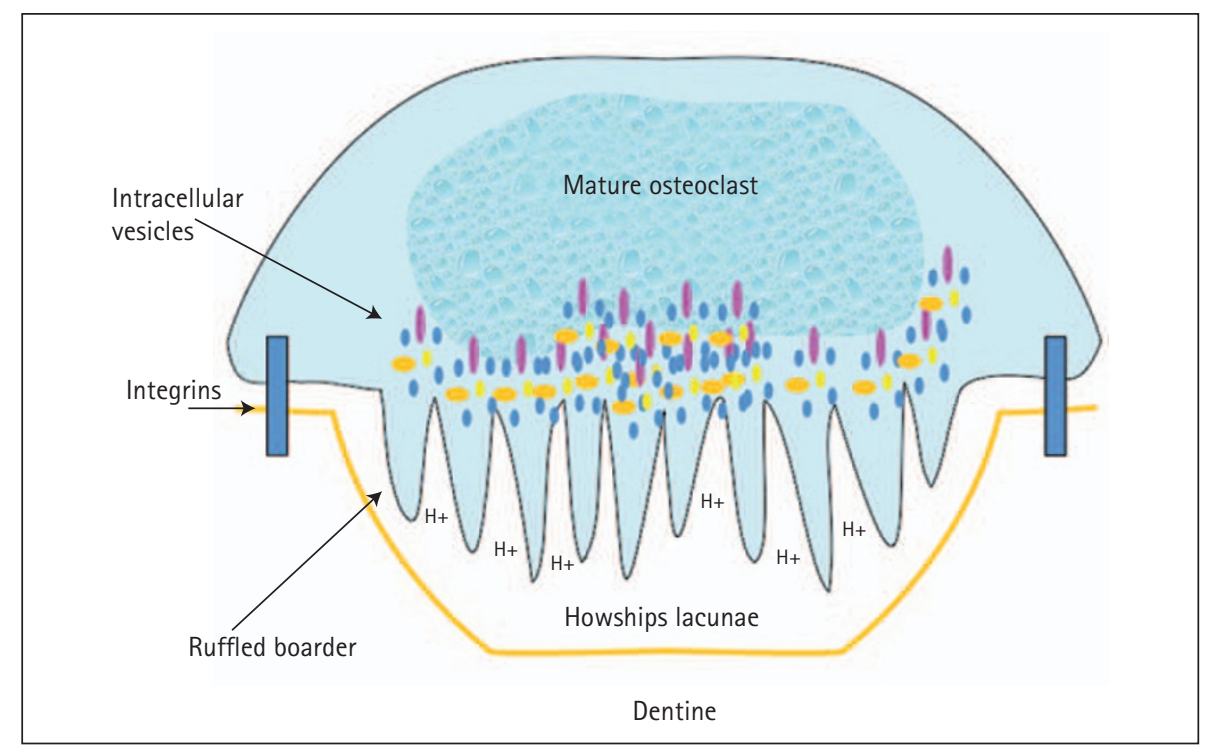

Fig. 1 A mature osteoclast; courtesy of Alan Jack, University of Manchester

Table 1 Analogous terminology in the description of resorptive lesions

\begin{tabular}{l|l}
\hline & Analogous terminology \\
\hline External surface resorption & $\begin{array}{l}\text { Surface resorption } \\
\text { Transient inflammatory resorption } \\
\text { Cemental healing }\end{array}$ \\
\hline \multirow{3}{*}{ External inflammatory resorption } & $\begin{array}{l}\text { Progressive external inflammatory resorption } \\
\text { External root resorption } \\
\text { Peripheral inflammatory root resorption } \\
\text { Periapical replacement resorption }\end{array}$ \\
\hline \multirow{2}{*}{ External replacement resorption } & $\begin{array}{l}\text { Ankylosis } \\
\text { Replacement resorption } \\
\text { Osseous replacement }\end{array}$ \\
\hline \multirow{2}{*}{ External cervical resorption } & $\begin{array}{l}\text { Invasive cervical resorption } \\
\text { Sub-epithelial external root resorption } \\
\text { Hyperplastic tooth resorption } \\
\text { Odontoclastoma } \\
\text { Extracanal invasive resorption } \\
\text { Sulcular infection } \\
\text { (and many more!) }\end{array}$ \\
\hline Internal surface resorption & Transient internal resorption \\
\hline Internal inflammatory resorption & $\begin{array}{l}\text { Progressive internal inflammatory resorption } \\
\text { Internal root resorption }\end{array}$ \\
\hline Internal replacement resorption & - \\
\hline
\end{tabular}

osteoclastic activity they are chemoattractants for leukocytes. ${ }^{25}$ In the presence of bacterial lipopolysaccharides leukocytes differentiate into osteoclasts. ${ }^{26}$ The genera Treponema, Porphyromonas and Prevotella have all been shown to have such surface lipopolysaccharide antigens. ${ }^{27-29}$ Certain Gram-positive species have also been demonstrated to stimulate osteoclast differentiation through both RANKL and RANKL-independent mechanisms. ${ }^{30,31}$

Osteoclastic activity is integral to both regular maintenance and repair of tissues. For example parathyroid hormone stimulates resorption to increase levels of circulating calcium: a normal response to depleted calcium. ${ }^{32}$ From a dental perspective physiological resorption is an essential process in the exfoliation of the primary dentition. There is a constant equilibrium between osteoclastic activators and inhibitors. When there is an insult to a tissue, cytokines are produced and the repair process includes osteoclastic activity. It is thought the RANKL system is integral to the process of repair in dental hard tissues. ${ }^{33}$ If tooth tissue is irretrievably damaged complete resorption may occur.

At a histological level resorption is common. ${ }^{34}$ When the attachment apparatus of a tooth is damaged or traumatised it is common for a resorptive process to follow 


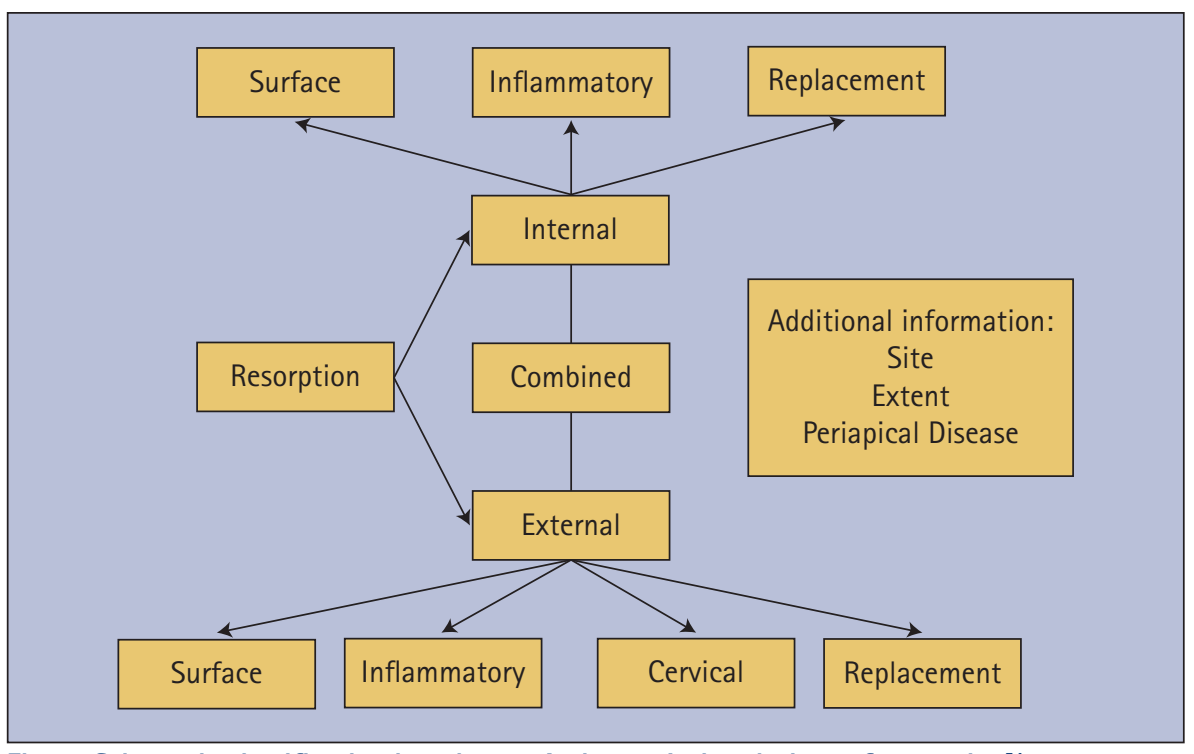

Fig. 2 Schematic classification based upon Andreasen's descriptions of resorption ${ }^{54}$

but unless the stimulation is continuous it will cease. ${ }^{35}$ In small lesions with no bacterial presence, this is followed by repair. ${ }^{34,36}$ Andreasen termed this simple, self-limiting process, external surface resorption. ${ }^{37}$ As it is often not clinically detectable the process may be significantly under-reported.

Clinically, resorptive lesions are rare. Biological protection mechanisms exist to prevent the resorption of teeth. These barriers being a vital periodontal ligament, healthy cementum and the extra-cellular predentine layer:

- Teeth with vital periodontal

membranes have been shown to undergo less resorption than those with necrotic periodontia. In experiments in which the periodontal ligament is selectively damaged/necrosed there is a greater incidence of resorption. The nature of the resorptive process has been suggested to be related to the size of the area of necrosed periodontal membrane. ${ }^{37}$ The healing capacity of the periodontal ligament may be up to $1.5 \mathrm{~mm}$ initially. Thus larger areas of damage may not heal and may be prone to resorption. ${ }^{37,38}$ It has also been shown that periodontal ligament cells can produce RANKL. It may be that damage to the periodontal ligament produces such a large inflammatory response that the cementoid layer is damaged too $^{39}$

- The presence of an intact cementum layer offers resistance to resorption, cementum being much more resistant to resorption than dentine. ${ }^{40}$ The external surface of cementum is formed by a layer of cementoblasts over a layer of cementoid. It may be that this non-mineralised layer is the barrier. In addition cementum is thought to lack those proteins found in bone that may stimulate osteoclastic activity. ${ }^{41}$ Furthermore it has also been postulated that cementum contains inhibitory factors for osteoclastic processes. ${ }^{42}$ Andreasen has hyposthesised that the fate of the cells closest to the root dentine, that is, the cementum, is significantly related to the process of resorption. ${ }^{37}$ Another function of cementum is to prevent the spread of bacteria and toxins from the dentine to periodontal ligament, which in turn prevents the initiation of an inflammatory response and possible resorptive activity. ${ }^{43}$ Thus, for resorption to occur there must be significant damage to the cementum

- Wedenberg and Linskog hypothesised that internal resistance to resorption is due to the presence of a noncollagenous component found in predentine. ${ }^{44}$ In a further study accumulation of marcophages was demonstrated on predentine and demineralised dentine when the tissue had been treated to remove organic components with guanidium hydrochloride. ${ }^{45}$ Thus it has been conjectured that the odontoblastic layer and surrounding predentine may also be inhibitory against resorption in a similar way to that seen on the external aspect of cementum. ${ }^{46}$ It has therefore been postulated that the creation of a predentinelike layer on the root surface can promote regeneration and new attachment and inhibit resorption. ${ }^{47}$ This can be achieved by the selective demineralisation with acid. ${ }^{48}$

It is thus evident that cementum and periodontal ligament are barriers to external root surface resorption and predentine to internal root surface resorption. Thus, the root is protected in its entirety. Damage to these barriers allows osteoclasts to bind to the root and if an inflammatory response occurs adjacent to the root surface this in turn may initiate resorption. It has been further postulated that prior activation and/or persistent stimulation is essential before resorption can proceed. ${ }^{3,53}$ Where the stimulus is persistent a clinical resorptive lesion may develop.

\section{CLASSIFICATION}

Resorptive lesions can be most simply classified as external or internal. In the former the lesion occurs on the external aspect of the root. In the latter the lesion occurs with the root upon the dentine of the root canal and/or pulp chamber. There have been many attempts to further classify resorptive lesions. Such classification systems are largely based upon the site and type of resorptive process. , $^{1,39-51}$ Classification may also be based upon the aetiology. 2,52,53 Many of these systems of classification relate to analogous terminologies (Table 1). The classification system as proposed by Andreasen is widely acknowledged and will form the basis of classification within this paper. ${ }^{54} \mathrm{~A}$ further category has been added into those conditions classified as external: external cervical resorption. ${ }^{55}$ This has been accepted as a pathological entity separate from other resorptive conditions. ${ }^{56}$

What follows is a more detailed description of the differing presentations of root resorption using this modified system of Andreassen's classification (Fig. 2).

\section{External surface resorption (ESR)}

This process is a consequence of localised and limited injury to the root surface or surrounding periodontium. ${ }^{37,57}$ It is a selflimiting process of osteoclastic activity for 
two to three weeks followed by root surface and cemental healing and reattachment of periodontal ligament. It has been defined as 'small superficial resorption cavities in the cementum and outermost layers of the dentine. ${ }^{34}$ When no further stimulation is present such resorptive cavities will heal uneventfully. ${ }^{58}$ If the resorptive cavity is only in cementum complete healing will occur but if the cavity is into dentine healing with new cementum follows and thus the contour of the root surface may only be partially restored. ${ }^{3,37}$ There is no significant inflammatory change though this process can continue if there is pulpal necrosis or infection. ${ }^{59}$ This process is thought to be exceedingly common but grossly underreported as it is sub-clinical. ${ }^{51}$

\section{External inflammatory resorption (EIR)}

Prolonged stimuli to areas of damaged/ denuded root surface allows continuation of the process of surface resorption. ${ }^{3}$ Andreasen proposes a series of four events necessary for this to occur: Firstly there must be trauma to the root surface; typically after replantation where there is damage to the periodontal ligament and extended drying of the root surface. Following this the exposure of the dentinal tubules into the resorptive cavity, which must communicate with an infective or necrotic pulp. Finally the age of the tooth must be considered with immature and younger teeth being more frequently affected. ${ }^{3}$ It may also occur with the application of pressure. Unchecked this process can completely resorb roots in months. (Figs 3a, 3b and 4)

\section{External cervical resorption (ECR)}

External cervical resorption is a localised resorptive lesion of the cervical area of the root below the epithelial attachment (thus it may not always be in the cervical region.). ${ }^{60}$ In a vital tooth unless the lesion is extensive there is rarely pulpal involvement. ${ }^{61}$ It is this feature that helps distinguish ECR from EIR; in the latter pulpal necrois or infection are prerequisites. ${ }^{3}$ As with all resorptive lesions there may only be a small area of activity upon the external aspect of the root but with a more lengthy stimulus the lesion may expand within the dentine (Fig. 5). This expansion can extend both coronally and apically, encircling the pulp (Fig. 6). ${ }^{62}$ Even in advanced lesions the pulp may remain protected by the predentine. Nonetheless, as the lesion progresses there may be significant tooth structure loss. ${ }^{60}$ The aetiology remains poorly understood and both inflammatory and infect processes have been implicated. ${ }^{63}$ Predisposing factors to the process include trauma, periodontal therapy and internal bleaching agents. ${ }^{55}$

ECR may affect multiple teeth in a process known as multiple idiopathic cervical resorption (MICR). ${ }^{64}$ This rare condition was first identified in 1930 by Mueller and Rony and has been infrequently described in the literature to date. ${ }^{65,66} \mathrm{MICR}$ affects a number of teeth (minimum three) in either a discrete area or more severely across the entire dentition. ${ }^{67}$ Patients are healthy with non-contributory medical histories. There does not appear to be any fully understood causative factor and case reports do not implicate any correlation with age, gender, ethnicity, genetic predisposition or medical history. One author has suggested a link to younger females ${ }^{68}$ but the low prevalence hinders the ability to draw such conclusions. It has been speculated that the condition may be related to trauma, intra canal bleeding and soft-tissue grafts. ${ }^{69}$ Clinically lesions are often asymptomatic with no inflammation. ${ }^{67}$ The presence of the condition in an impacted tooth precludes the possibility of a bacterial cause. It has been speculated to be related to the feline herpes virus 1 though this has not been proven. The lesions have been shown to progress irrespective of intervention (Fig. 7). ${ }^{66,69}$

\section{External replacement resorption (ERR)}

This is the process of replacement of root surface with bone otherwise known as ankylosis. The aetiology remains poorly understood. ${ }^{70}$ This may be considered a homeostatic process of bony remodelling following union of bone and dentine (differing from EIR, which is essentially a pathological process). ${ }^{71}$ Bony trabeculae develop within the periodontal ligament space and fuse to the root surface. ${ }^{59,72}$ After initial contact of a bone bridge onto the root surface further bony cells will invade the root from the adjacent socket. ${ }^{70}$ ERR may be further categorised as transient or progressive. ${ }^{3}$ The former is self-limiting;
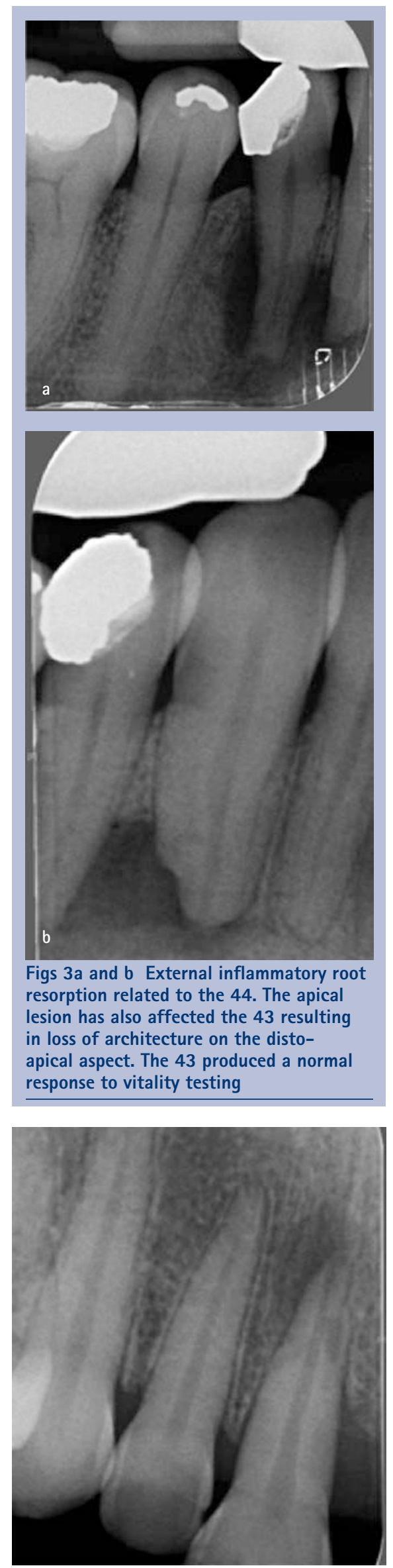

Fig. 4 History of replantation 11 without endodontic therapy. There is alteration of the apical root form with an associated osteolytic area of bone: consistent with EIR 


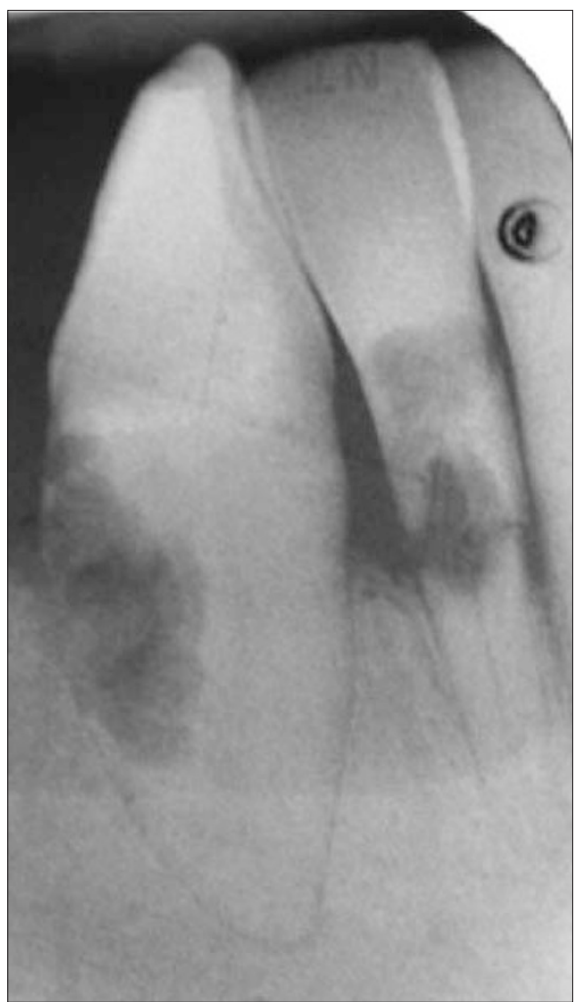

Fig. 5 There is cervical resorption occurring on both 43 and 42.42 also appears to have an internal resorptive process more apical to the cervical lesion, with a horizontal fracture present. $\mathbf{4 2}$ was clinically grade II mobile

resulting from a combination of only minor areas of periodontal ligament damage and the healing capacity of adjacent periodontium..$^{73,74}$ The latter is a continual process resulting in complete resorption of the root due to extensive or complete loss of the periodontal ligament (Figs 7 and 8). The rate of ERR varies according to age and growth rate of the patient. ${ }^{75,76}$ Following the onset of ERR the tooth may be lost in three to seven years in patients aged 7-16, but in adults the tooth may survive 20 years. $^{75}$

\section{Internal root resorption}

This process takes place within the canal system. It has been described as apical or intra-radicular. ${ }^{16}$ Internal apical resorption is associated periapical pathology and is common. ${ }^{51}$ It may be regarded as advancement of external inflammatory resorption into the root canal: ${ }^{77}$ throughout this review apical resorption will be regarded as presentation EIR. When not associated with the apical area this is a relatively rare condition..$^{54,78}$ It is thought to be more prevalent in males than female patients., ${ }^{479}$ The precise aetiological and pathological mechanisms remain poorly

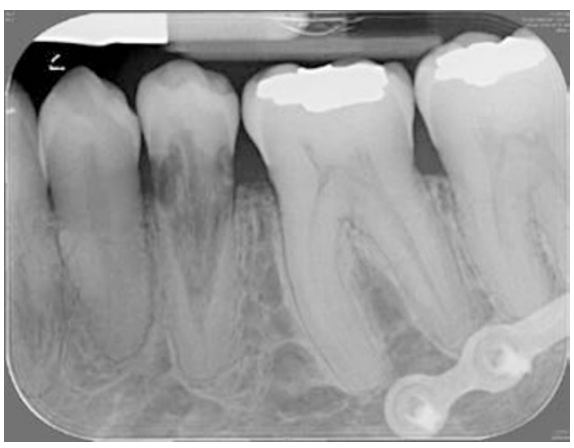

Fig. 6 Extensive ECR associated with the 35 . Note the preservation of the root canal within the lesion

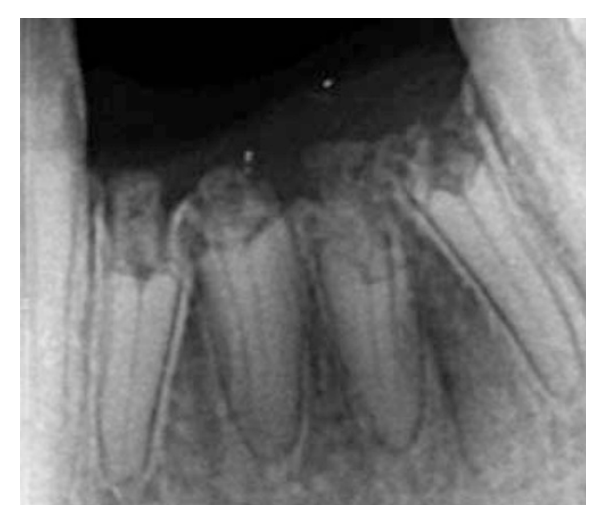

Fig. 7 All lower incisors have suffered pathological fractures. In the absence of any known aetiology this may be multiple idiopathic cervical resorption

understood. ${ }^{52}$ There maybe an association between internal resorption and traumatised/replanted teeth or those teeth that have undergone pulpotomy and crown preparations as all these processes may damage predentine and allow osteoclastic action on the underlying dentine. ${ }^{80}$ There must be vital pulp tissue apical to the osteoclasts to provide a blood supply for nutrients and necrotic/infected tissue coronal to the osteoclasts to maintain stimulation. ${ }^{81}$ Is has been described as being transient or progressive. ${ }^{82}$ Three sub-categories have been described:

\section{Internal surface resorption (ISR)}

This process is analogous with external surface resorption. Osteoclastic activity is initiated but arrests. It is self-limiting without further stimulation. ${ }^{82}$

\section{Internal inflammatory resorption (IIR)}

Characterised by ovoid or fusiform enlargement of pulp chamber or root canal (Fig. 9). The enlargement typically expands in an apical and lateral direction. There may be chronic pulpal inflammation. ${ }^{81}$ This process may be analogous with EIR.

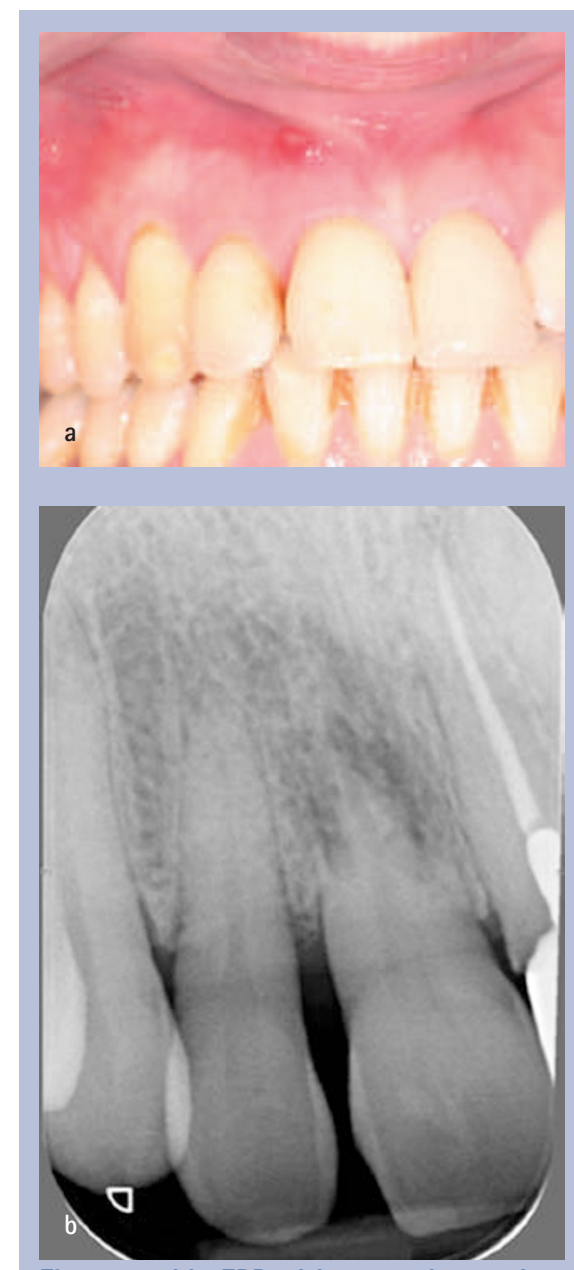

Figs 8a and b ERR with a superimposed periradicular periodontitis eight months after replantation of 11

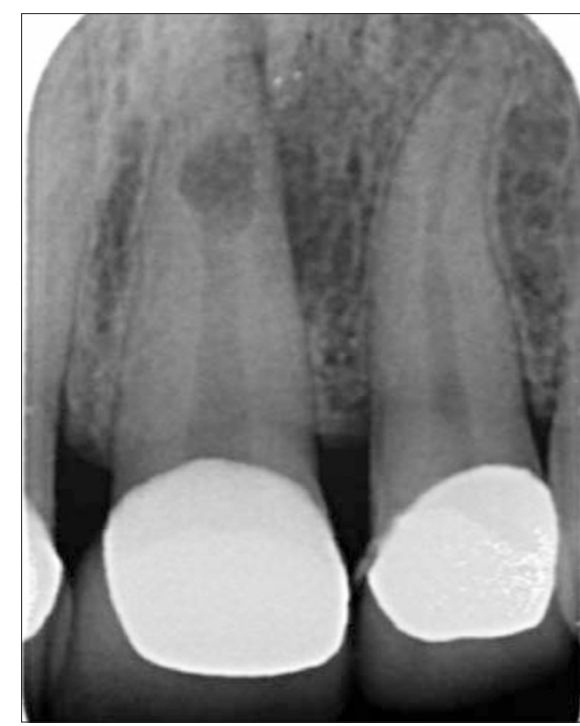

Fig. 9 Resorption of the dentine within 21 presents as expansion of the root canal

Internal replacement root resorption (IRR)

Internal replacement root resorption is rare. ${ }^{83}$ There may be more irregular enlargement of the canal space. There are diffuse 
areas of mixed radiolucencies and radioopacities reflecting metaplastic changes.$^{80}$ It may lead to obliteration of the canals space with cancellous-like bone. There is uncertainty as to why this process occurs. It may be that dental pulp stem cells produce the osteoid material as a reparative response to trauma, inflammation or bacteria. A second theory purposes that the cells are non-pulpal in origin and have migrated into the pulp from the periapical tissue via capillaries. ${ }^{81}$

\section{AETIOLOGY}

\section{Pulpal disease and peri-radicular or apical pathosis}

Caries or mechanical trauma will elicit an inflammatory process within the pulpal tissue. This results in the production of nonspecific inflammatory mediators. If there is damage to the protective predentine layer osteoclasts may bind to the dentine. In the presence of such inflammation osteoclastic activity may be stimulated resulting in internal resorption. ${ }^{82,84} \mathrm{~A}$ blood supply is required to maintain the inflammatory process so there must be vital (but possibly inflamed) pulp tissue apical to all sites of resorption. Coronal to this, the pulp tissue must be partially or completely necrotic. ${ }^{51}$ The resulting resorptive process spreads into the dentine around the pulp apically and laterally to the necrotic area. It arrests unless there is a microbial stimulus. Gram-positive bacteria and spirochaetes have been found to stimulate RANKL expression and thus perpetuate the process. ${ }^{46}$ Once the pulp has become completely necrotic the internal resorptive process will cease. ${ }^{51}$ It has been suggested that resorptive processes may still continue in the necrotic pulp if there are accessory canals that may still provide nutrients for osteoclasts. ${ }^{85}$ As described above, this process of internal resorption may be inflammatory or replacement in nature. In the latter case not only is there resorption of dentine but deposition of osteoid and cementum-like material. ${ }^{80}$ It would not appear possible to predict what pattern of resorption may follow. ${ }^{81}$

After complete necrosis of the pulp, resorption may occur apically. The term internal apical resorption describes resorption of the apical portion of the canal but it has been suggested that this is more appropriately regarded as a continuum of an EIR

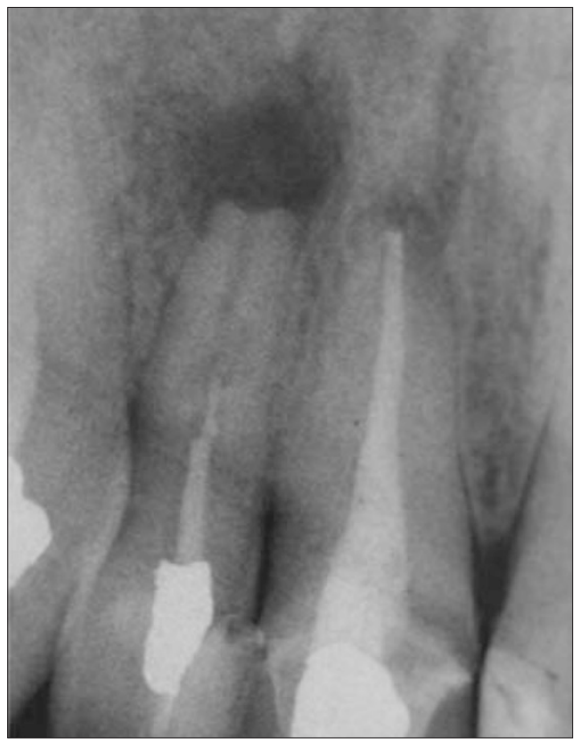

Fig. 10 Periapical periodontitis 12 with EIR apically

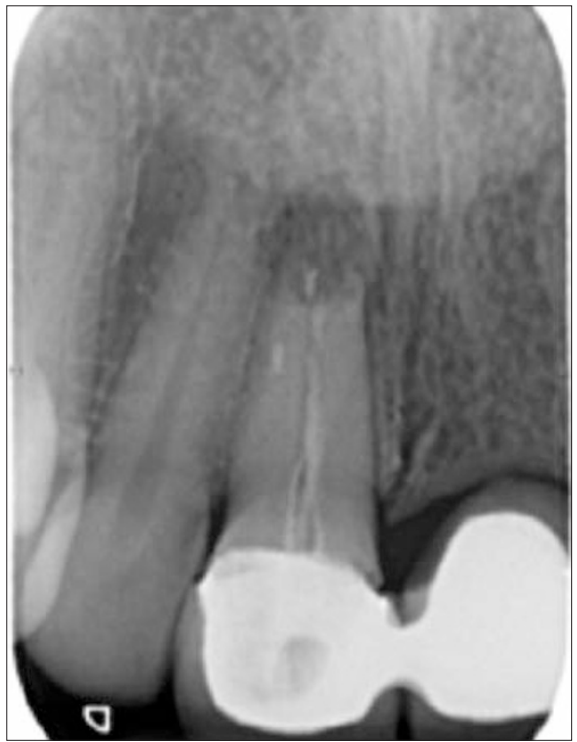

Fig. 11 Persistent periapical periodontitis of the 11 with loss of local architecture and blunting of the apex: EIR

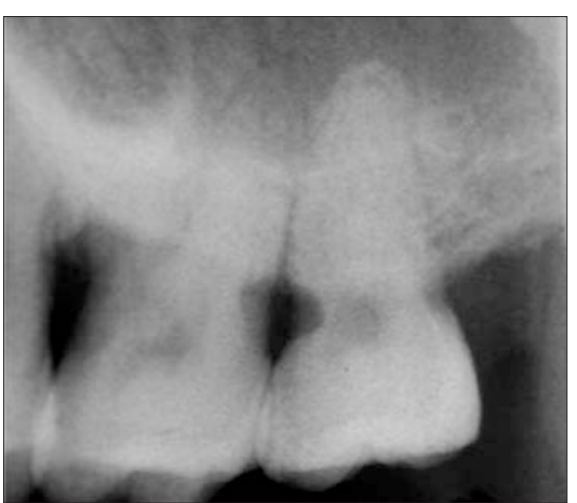

Fig. 12 This lesion on the mesial aspect of the $\mathbf{2 7}$ was provisionally diagnosed as an external inflammatory resorptive lesion associated with the patient's periodontal condition. Surgical exploration revealed a large, non-carious surface defect on the mesial root surface

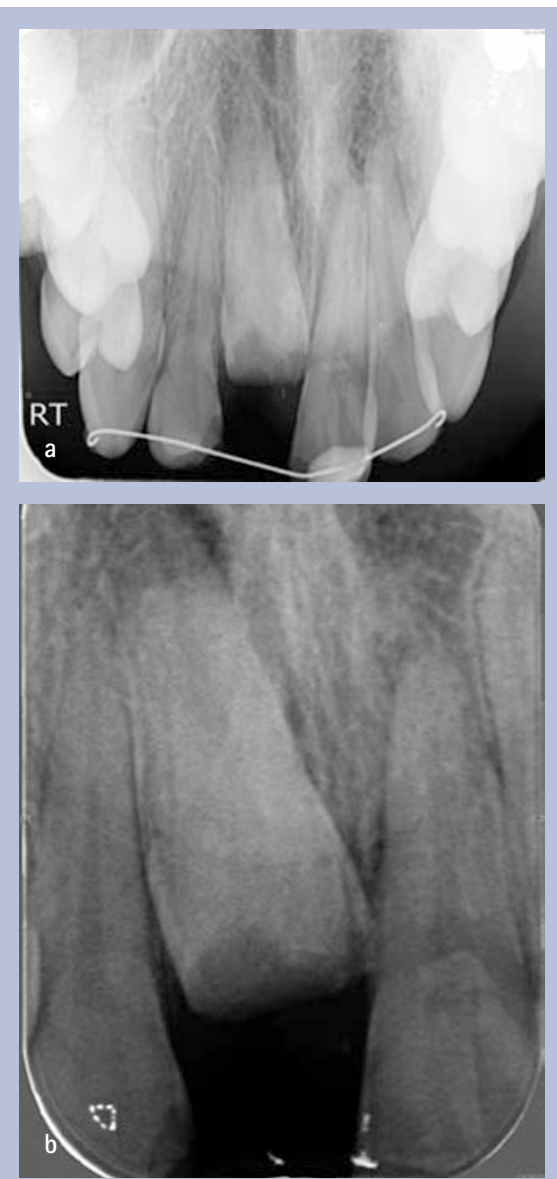

Figs 13a and b A severe intrusion injury to 11 . External resorption is likely on this tooth

rather than an internal process. ${ }^{81}$ Apical inflammatory root resorption is a common descriptor of this process but throughout this paper it shall be regarded as presentation of EIR (Fig. 10). It has been proposed osteoclasts readily bind in the apical zone as there maybe exposed dentine. ${ }^{86} \mathrm{~A}$ wide collection of microorganisms may be related to the stimulation of osteoclasts as many species express RANKL, prostoglandins and lipopolysaccarides. These include: Prevotella intermedia, P. nigrescens, Treponemas, Porphyromonas, Staphylococcus and Streptococci..$^{27,30,87}$ Resorption in this region may be further stimulated by pressure from expanding periapical granuloma or cyst.

Tronstad hypothesised that "practically all teeth with apical periodontitis will exhibit apical resorption. ${ }^{51}$ Up to $75 \%$ of teeth with periapical periodontiis may demonstrate histological evidence of EIR in the apical region (Fig. 11). ${ }^{77}$ Clinical examination may not yield such a high prevalence. ${ }^{88}$ Conventional radiography may not be sufficiently sensitive to permit diagnosis of 


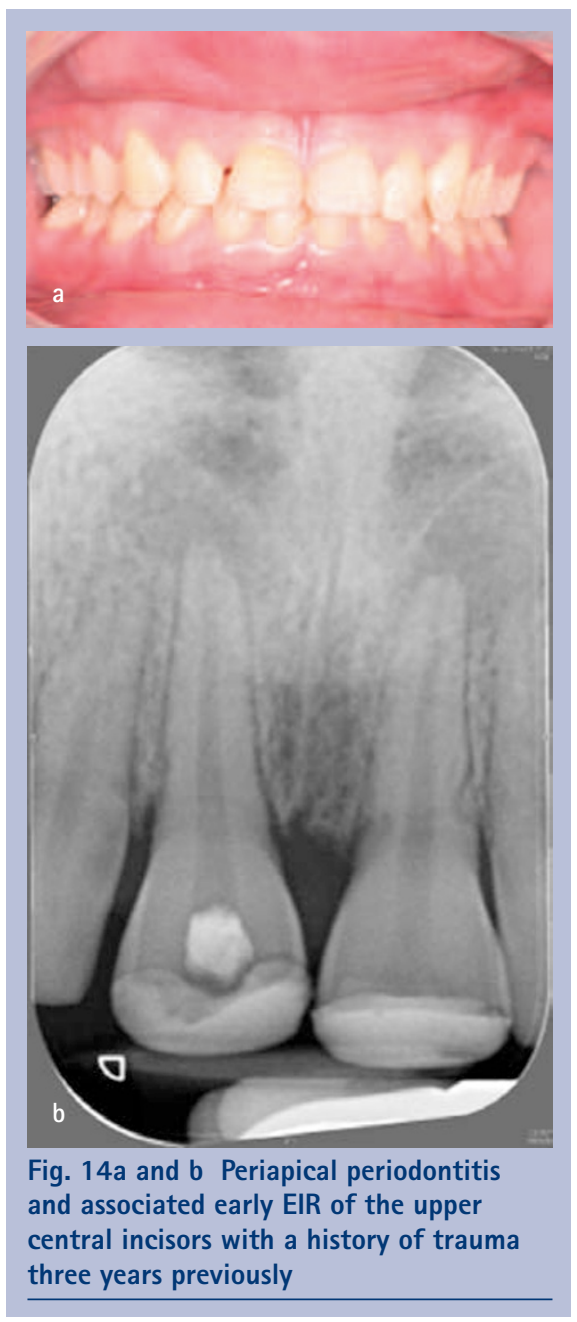

many such lesions. Furthermore, many teeth with periapical lesions do not display signs of resorption. There are stem cells within the apical papilla and it could be that this region has a better capacity for repair, thus there may be a balance of resorptive and odontoblastic processes ongoing in this zone. ${ }^{89}$

\section{Periodontal disease}

When gingivitis is present there is a low grade, continual inflammatory process within the marginal gingivae in response to persistent challenge of bacterial plaque. When this process leads to apical migration of the epithelial attachment, loss of collagen attachment and loss of bone the inflammatory process results in a periodontitis. ${ }^{90}$ Apical migration of the attachment apparatus exposes the root surface. Post therapy new cells may populate the area from any of the adjacent tissues including gingival epithelium, alveolar bone and non-injured periodontium. Ideally there would be coronal regeneration of the periodontal ligament to protect the root surface but more commonly there

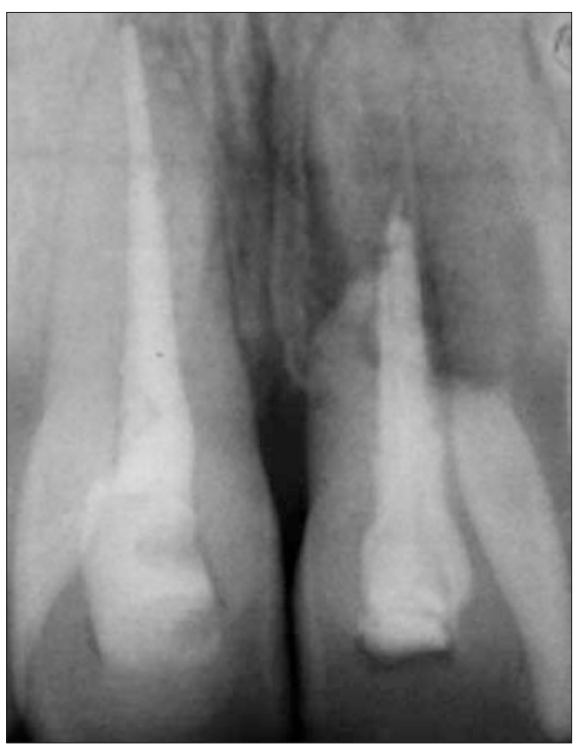

Fig. 15 EIR post trauma. The progression of this lesion may be due to poor quality root canal treatment

is apical proliferation to a long junctional epithelium. Down growth of epithelium has been hypothesised as providing a barrier to resorptive processes. ${ }^{91}$ If cells from the alveolar bone contact the root surface, resorption may occur. ${ }^{92}$ Despite this, resorption rarely occurs in these sites. Beertsen reported that damage to the junctional epithelium in the presence of a chronic inflammatory process can result in a resorption (Fig. 12)..$^{93}$

\section{Trauma}

Traumatic injuries to teeth may result in resorption. ${ }^{54,78}$ For this to occur there must be damage to the protective barriers, cementum and/or periodontal ligament. The likelihood and extent of resorption is related to the extent of damage to these barriers. ${ }^{38}$ Damage to cellular cementum is most significantly related to the onset of resorption. The quantitative surface area of tissue damage is correlated with the type of resorption that may ensue: larger areas of cellular damage heal with osteogenesis and thus external replacement resorption may follow. ${ }^{37}$ When considering the injury, complete avulsion is not thought to be the most significant cause of cemental damage as most trauma is to the periodontium. Most damage follows apical intrusion due to the crushing of cemental cells as root surface and bony crypt collide; ${ }^{94}$ the convex surfaces are most likely to receive the greatest trauma. ${ }^{37}$ Intrusion is the greatest cause of unfavourable healing posttrauma, followed by avulsion, lateral

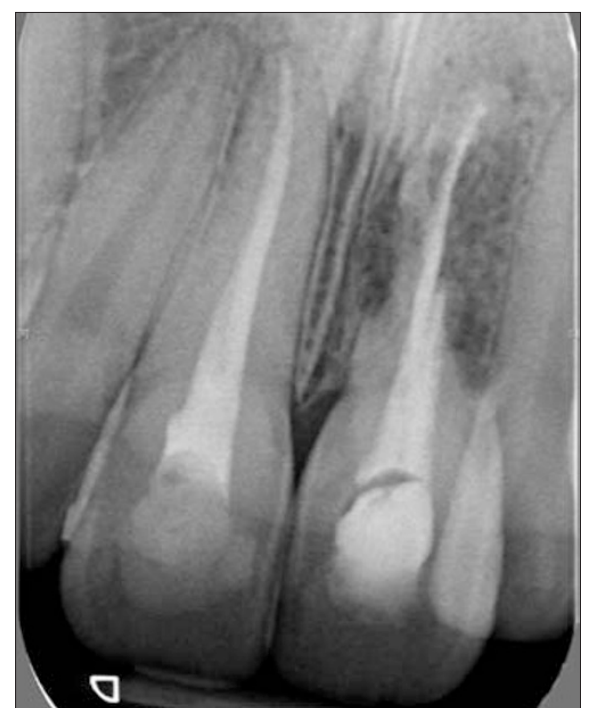

Fig. 16 Following a history of trauma to the 21 there is loss of lamina dura, ragged dentinal margins and evident bony infiltration indicating ERR

luxation, extrusive luxation, subluxation and concussion (Figs 13a and b). ${ }^{39}$

The management of the tooth post injury must, however, be considered as significant in the aetiology of resorption. The duration of time between avulsion and replantation and the choice of storage medium before replantation are both critical for the survival of cementum and periodontal ligament. ${ }^{94,95}$ Replantation after an extra-oral period of 15 minutes in air at room temperature may result in favourable healing but an hour under the same conditions may result in extensive ERR. ${ }^{70}$ This period can be prolonged if the tooth is kept from desiccation ${ }^{96}$ and prolonged further if stored in an appropriate medium. ${ }^{94}$ Though cemental damage may be minimal after avulsion, damage to and subsequent inflammation of the periodontal ligament will result in an extensive inflammatory response upon replantation and thus a high risk of resorption. ${ }^{37,95}$ This is initiated by many factors including: the damaged root surface itself and bacteria and foreign bodies introduced on to the root surface during the period of avulsion. If a vascular supply is not maintained post implantation pulp necrosis will follow. Following the loss of cementum, bacteria and toxic products may penetrate the dentinal tubules onto the root surface, stimulating osteoclasts and EIR may occur (Figs 14a and b and 15). ${ }^{39}$ This may be more significant in younger patients as the tubules may have greater patency. ${ }^{34,36}$ If the damage is in the cervical region this may initiate ECR..$^{39,62}$ 
If the stimulus to resorption is shortlived or self limiting a healing process may result over the subsequent 14 days. ${ }^{97}$ In small isolated areas cementoblasts may repopulate the root surface. This process is termed external surface resorption (as described above) and is ultimately the most favourable outcome. ${ }^{34,36,84}$ If, however, bone cells are allowed to repopulate the root surface, bone will develop directly on the root surface in the process known as external replacement resorption (ERR). This may occur if greater than 20\% of the root surface is irreversibly damaged. ${ }^{38}$ As bone remodelling and turnover is a constant process this balance of osteoclastic and osteoblastic activity can lead to the gradual replacement of root dentine with bone. In progressive cases nothing can be done to terminate this process (Fig. 16). ${ }^{71}$

\section{Pressure}

There are considered to be two principal initiators of resorption related to pressure. The iatrogenic stimulus of orthodontics and the patho-physiological stimulus of impacted teeth or tumours. ${ }^{39}$ These processes are thought to be sterile ${ }^{39}$ and stem from inflammatory processes concerning localised pressure zones on the cementum or predentin of the apical region.

\section{ORTHODONTICS}

Resorption has been reported in 19-31.4\% of all patients undergoing orthodontic treatment, its prevalence being highest in mandibular and maxillary incisors, with molar and canines being least effected. ${ }^{98,99}$ One study presented in a small sample that post-orthodontics there was a loss of boney support from a combination of both marginal bone loss and root resorption in the order of 1-1.5 mm. They proposed it was of such small magnitude as to be negligible when balanced by the benefits of orthodontic treatment. They further proposed that individual predisposing factors were more likely to be responsible, most notably a history of trauma. ${ }^{100,101}$ In 1991 Linge and Linge reported up to $2.5 \mathrm{~mm}$ of root reduction after orthodontic treatment. ${ }^{102}$ This may be because incisors tend to be moved further. One meta-analysis has indicated the apical distance moved and duration of orthodontic treatment is correlated to the mean apical resorption. ${ }^{103}$
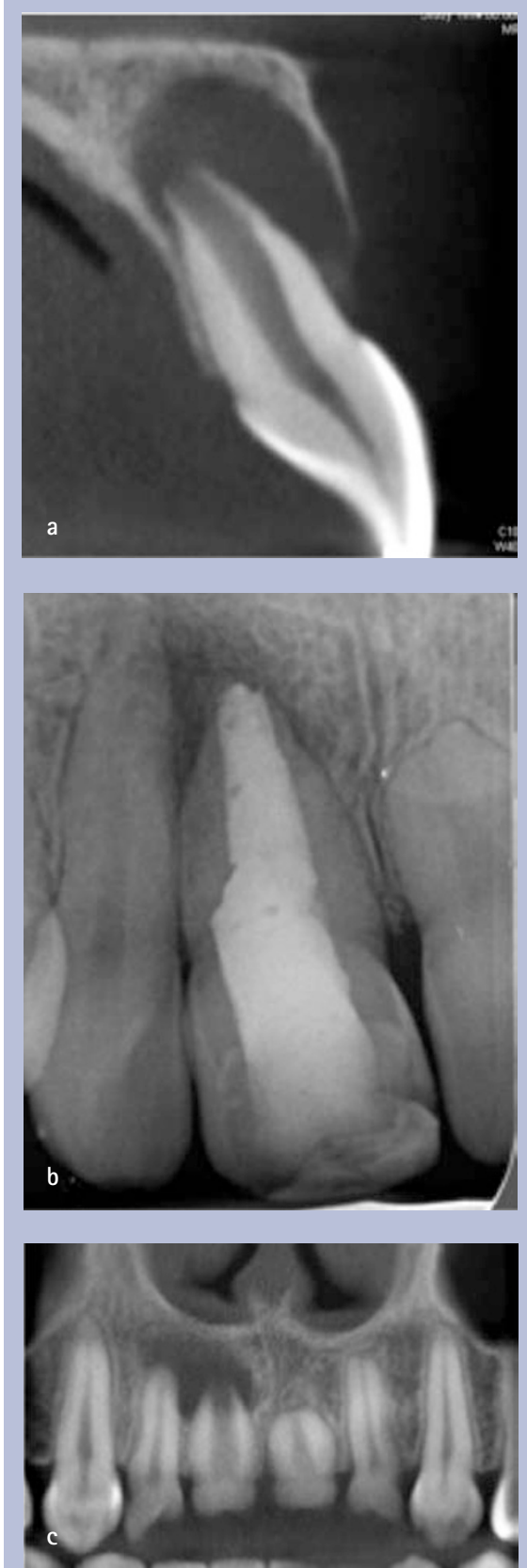

Figs 17a-c Post orthodontic treatment there is blunting of the roots 22-12 and a frank periapical lesion 11 with arrested root development. A traumatic component may have influenced the progression of this lesion. The 11 was treated with apical MTA placement. All images from a limited volume cone beam $\mathrm{CT}$ examination

When occurring in adult patients it may be more extreme. ${ }^{104}$ Ankylosis does not tend to occur with orthodontic related resorption and the periodontal ligament remains intact. ${ }^{105}$ Maintenance of vitality in orthodontically treated teeth is variable (Figs 17a-c). ${ }^{106}$

In well planned orthodontic treatment the forces applied to the teeth should be relatively evenly spread over the root
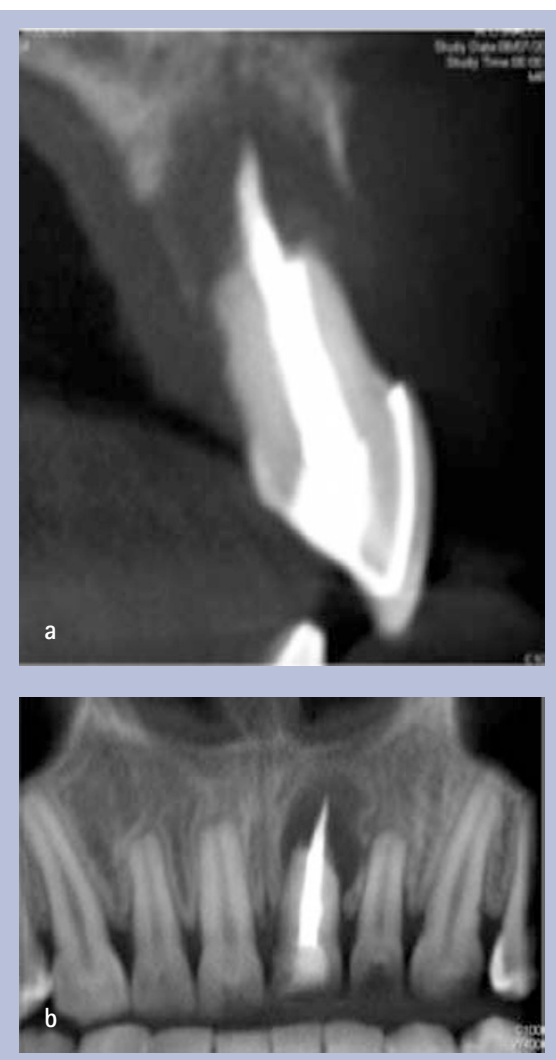

Figs $18 \mathrm{a}$ and $\mathrm{b}$ EIR pertaining to orthodontic treatment. All the incisor roots are foreshortened and blunt. There is a history of trauma to the 21 . Both images from a limited volume cone beam CT examination

surface. There are, however, instances in which the forces can be focal and greater around certain regions. It has been shown that the stimulus by such forces compresses the periodontal ligament inducing areas of hyalinised tissue. ${ }^{107}$ Under the hyalinised zones tissue may become necrotic initiating an inflammatory process. ${ }^{108}$ In addition it has been shown that compressed periodontal cells produce RANKL, stimulating the development of osteoclastic cells. ${ }^{109}$ Multinucleate osteoclastic cells move into the necrotic zones and once necrotic tissue has been removed they attack cementum. Once the protective cementoid is removed the root becomes vulnerable and resorption commences. ${ }^{110,111}$ Until all necrotic tissue is removed the process may continue, irrespective of cessation of orthodontic movement. ${ }^{11}$ A further explanation has been proposed in relation to the neurophysiology of the pulpal tissues. The neural supply of A-delta and C-fibres to the pulp and periodontium release neuropeptides when stimulated orthodontically. 


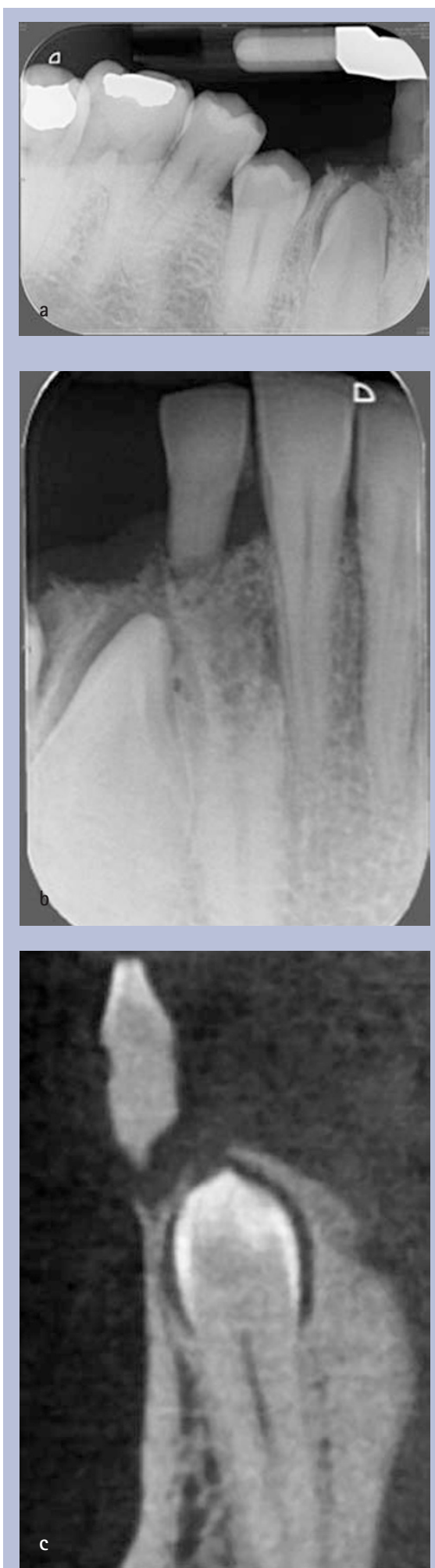

Figs 19a-c Extensive EIR of the 42 associated with an unerupted $43.19 \mathrm{c}$ is a reformatted image from a limited volume cone beam CT examination

These include Substance P, calcitonin gene-related peptide, neuropeptide $\mathrm{Y}$ and neurokinin A. These are prominent mediators of increased vascularity locally. Such changes in vascularity may be linked to osteoclastic activity by speeding recruitment of inflammatory cells. ${ }^{105}$
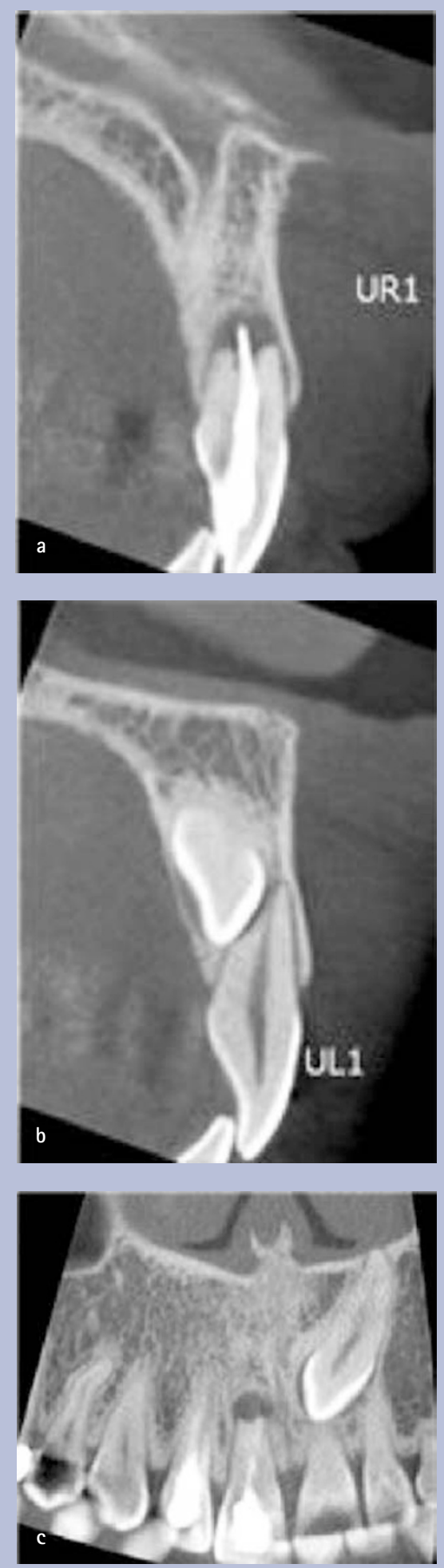

Figs 20a-c EIR resorption on the apex of the 21 from an unerupted 23. There is EIR apically on the 11 also. It is unlikely such a precise diagnosis could have been made without CBCT

Most often this is transient and clinically insignificant. ${ }^{105}$ This is perhaps due in part to the discontinuous nature of the applied force: during orthodontics there are typically periods of increased stress, trauma and compression of the periodontal ligament when appliances are activated and reactivated. Between such periods stresses reduce allowing recovery of traumatised cells. It may also be due to the reparative capacity of the cells of the apical papilla. ${ }^{89}$ If, however, such processes occur apically it can be more marked resulting in a blunting of the apex or in severe cases severe loss of root length (Figs 17a-c). ${ }^{102}$ This may be due to the combination of EIR around apical cementum and IIR of apical predentine. ${ }^{100}$ Resorption associated with orthodontic tooth movement is thought to be multifactorial. ${ }^{112}$ Genetic tendencies and history of trauma appear to be most often associated with this pattern of resorption (Figs. 18a and b). ${ }^{113}$ This type of resorption has been named periapical replacement resorption (PARR) ${ }^{105}$ but throughout this paper it shall be recognised as a sub category of EIR.

Orthodontic tooth movement has also been highlighted as a possible factor in the development of external cervical resorption. ${ }^{62}$ In a study of 222 patients Heithersay $^{62}$ identified orthodontic treatment as the most common predisposing factor in cases of ECR. Excessive forces in the cervical region may induce necrosis and inflammation adjacent to dentine. Odontoclastic differentiation ensues followed by resorption. ${ }^{62}$ The onset of ECR in these patients has been demonstrated to occur after completion of orthodontic treatment. As such it is thought that the predisposition to ECR in these instances is due to a combination of factors rather than orthodontics alone. ${ }^{62,112}$

\section{IMPACTED TEETH/EXPANDING PATHOLOGICAL LESIONS}

The same principles related to orthodontic resorption are thought to be responsible for other 'pressure' resorption lesions associated with ectopic teeth and expanding infra-bony pathoses including cysts, giant cell tumours, fibro-osseous lesions and amelobastomas. Tooth impaction is a common phenomenon. ${ }^{114}$ Impacted/ectopic teeth may stimulate resorptive processes if the follicular space encroaches upon the periodontia of an adjacent tooth (Figs 19a-c and $20 \mathrm{a}-\mathrm{c}){ }^{115,116}$ It has been estimated that 0.6-0.8\% of 10-13-year-old children with canine ectopica have some degree of resorption of the incisors. ${ }^{117}$ Up to two thirds of incisors adjacent to impacted canines show evidence of resorption using CBCT. ${ }^{118}$

With slowly expanding lesions the 
resorptive pattern is often focal and well defined. If the lesions are expanding quickly the resorptive potential appears much more limited. Thus the presence of intact roots within an expanding bony pathology is indicative of a rapidly enlarging lesion. Often in malignancies the resorption pattern is 'raggedy' as the lesion expands around the root. Pressure has been implicated in the aetiology of cervical resorption in two case reports of wind instrument players. Though exceedingly rare clinicians should remain open-minded when considering possible causative factors in such poorly understood diseases (Figs 21a and b and 22). ${ }^{119}$

\section{Temperature}

Ultrasonic devices and warm obturation techniques are known to generate potentially high temperatures locally. Inflammatory tissue responses have been demonstrated to local temperature increases above $47{ }^{\circ} \mathrm{C}$ and tissue necrosis to temperature rises above $60{ }^{\circ} \mathrm{C} .{ }^{120}$ It has been further shown that warm obturation techniques can result in ankylosis (Fig. 23). ${ }^{121}$ Rises in temperature have also shown to upregulate pro-resorptive inflammatory mediators including RANKL and OPG from periodontal ligament cells. ${ }^{122}$ It has been thought that heated systems for endodontics may be hazardous if set to temperatures greater than $250{ }^{\circ} \mathrm{C} .{ }^{123}$ Although there is limited literature concerning correlations in raised intra-canal temperatures and resorption a theoretical association is reasonable.

\section{Chemical}

Given the expansion of cosmetic dentistry an increasing number of patients are demanding whiter teeth. With the increased number of patients using bleaching products a correlation has been seen with reports of resorption. ${ }^{55,124,125}$ It is known that the interface between enamel and cementum may not be continuous ${ }^{126}$ and thus open dentinal tubules in the cervical portion of the tooth may present a pathway for not only ingress but egress of substances and bacteria. Thus it is thought that during internal bleaching whitening products pass through dentinal tubules into the cervical periodontia. ${ }^{124}$ Friedman found in a study of 58 teeth treated with internal bleaching that 4 developed resorptive lesions
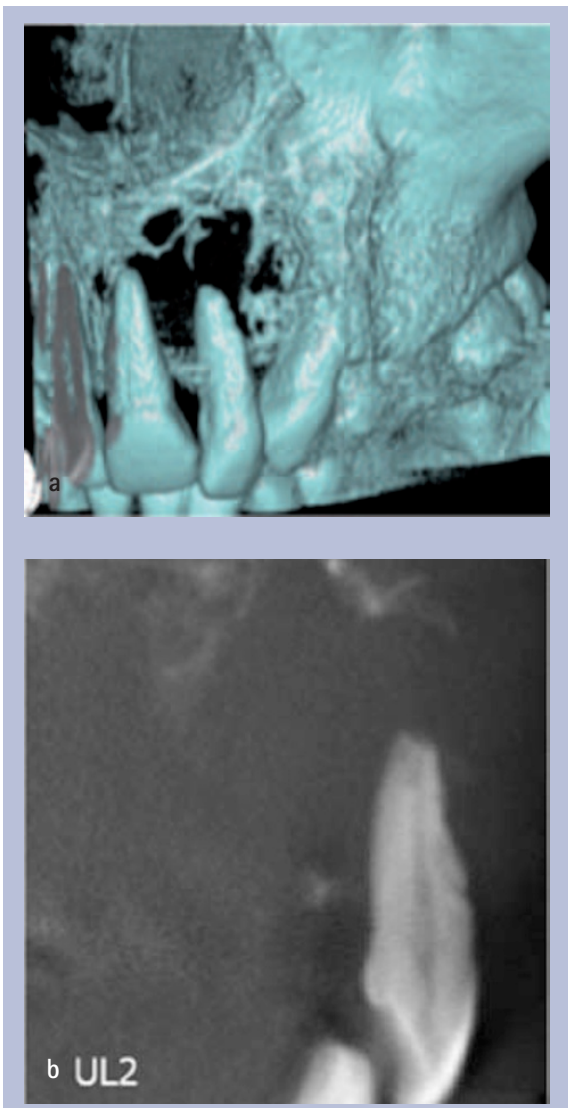

Figs 21 a and b A pressure-type resorption on the apices of the 21 and 22. The 21 , 22 and 23 were all non-vital. This was part of a known metastatic lesion in this patient's L maxilla

cervically. ${ }^{127}$ His review of these cases supported the notion of cervical passage of bleaching products to the periodontia but the precise cause of resorption could only be speculated. ${ }^{127}$ It may be that the products provoke an inflammatory response but further suggestions have been made that hydrogen peroxide denatures dentine and initiates an immune response or lowers the $\mathrm{pH}$ to a point that stimulates osteoclastic activity. ${ }^{124,128,129}$ Indeed it has been postulated that an acidic intra-oral environment can trigger resorption..$^{93,130}$ There has been a case of ECR in a patient whose only predisposing factor was an acid rich diet. ${ }^{93}$ Nonetheless the precise mechanism behind this pathology remains unclear. ${ }^{131}$ The process may be perpetuated by bacterial presence within local pockets or simply in the sulcus. Heithersay ${ }^{132}$ estimated bleaching to be the sole predisposing factor in up to $13.6 \%$ of cervical cases. It is further postulated that $2 \%$ of all patients undergoing bleaching in root filled teeth may develop resorption. ${ }^{132}$ The placement of rubber dam clamps and the use of lamps to accelerate

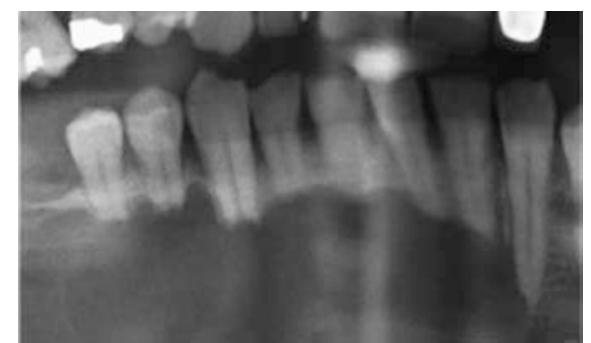

Fig. 22 Extensive resorption of the 45, 44, $43,42,41,31,32,33$ associated with an expanding odontogenic keratocyst of the mandible

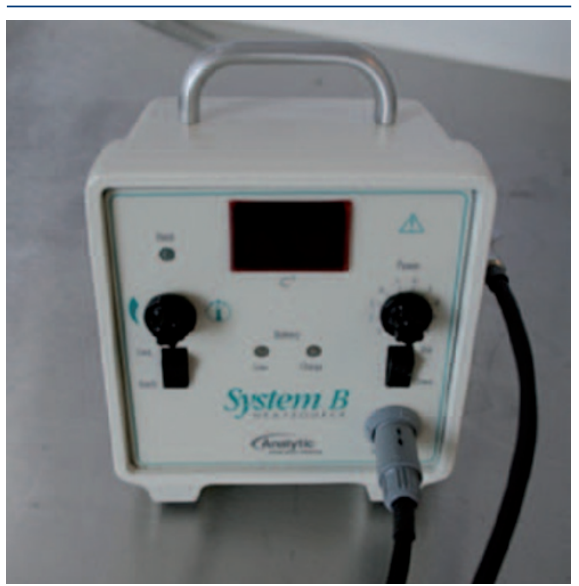

Fig. 23 System B (SybronEndo): capable of reaching temperatures in excess of $600{ }^{\circ} \mathrm{C}$

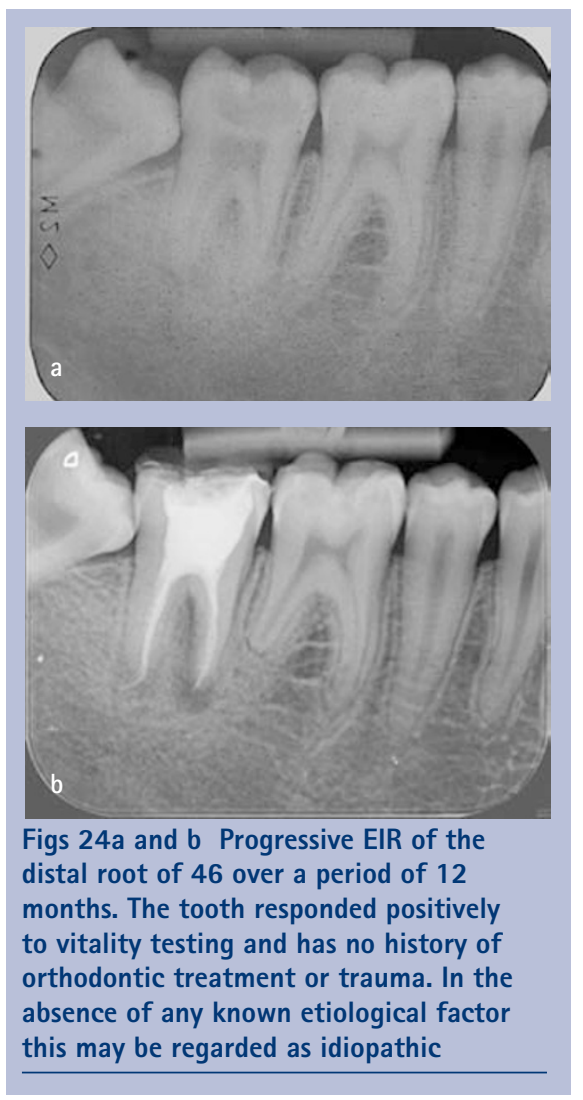

whitening procedures has also been shown to damage to the cervical region and these factors may also be correlated to the initiation of cervical resorption. ${ }^{124}$ 


\section{Viral}

A condition similar to multiple idiopathic cervical resorption is seen in captive, domestic and wild cats. These are known as feline odontoclastic resorptive lesions (FORL). ${ }^{133,134}$ The presentation would appear to be very similar to that in humans. Very little is known about either disease. In a series of four cases of multiple idiopathic cervical resorption, Von Arx et al. ${ }^{135}$ described a potential link with the feline herpes virus. In two of these reported cases the patients had pet cats that were both known to have loss of teeth with a pattern similar to FORL. One of these was confirmed as a case of FORL. ${ }^{135}$ As both conditions are extremely rare there are obviously insufficient cases to draw definitive conclusions but as the disease pattern is so similar the proposition is reasonable.

A viral link has been postulated by other authors. Soloman et al. ${ }^{136}$ presented a case of a patient suffering cervical resorptive lesions in two teeth. The patient had a positive history of herpes zoster in the corresponding division of the maxillary trigeminal nerve. ${ }^{136}$ Ramchandani and Mellor ${ }^{137}$ report a similar case of multiple cervical resorptive lesions in a patient whose only other relevant history was a bout of shingles associated again with the corresponding region of sensory innervation. Two cases reports are clearly an insufficient basis for an association but consideration should be given to any potential correlations with resorptive patterns and a patient's other relevant history where no other cause can be established.

\section{Systemic disease}

There are certain metabolic disorders that may be associated with resorptive lesions. Hyperparathyroidism is a rare condition usually associated with adenomas of the parathyroid gland. Over production of parathyroid hormone stimulates resorption leading to systemic hard tissue decalcification and cyst-like lesions within bones. It has been suggested this disease process may also result in increased dental hard tissue resorptive tendencies. ${ }^{138}$ Though not resorption per se, loss of the lamina dura is a common finding in these patients.

\section{Idiopathic}

There have been several reports of idiopathic resorptive processes in teeth. ${ }^{6-69} \mathrm{By}$ definition in these conditions there is no evident aetiological factor. It is thought the process involves the destruction of dentine followed by creation of a bony matrix within the resorptive cavity. There may be a genetic component. ${ }^{69}$ Possibly this is related to genetic alterations in interleukin 1B (Figs 24a and b). ${ }^{24}$

\section{Physiological}

Although root resorption in the adult teeth is a pathological process in the primary teeth it is an essential physiological process for tooth exfoliation. The location and extent of the resorptive process is dependent upon the path of eruption of the permanent successors. Incisors and canines erupt lingual or palatal to their primary predecessors and as such the crowns and pulps of these teeth may remain sound at exfoliation. Premolars erupt between the roots of the primary molars and there is more profound resorption into the pulp chamber. The process itself is less well understood than inflammatory resorption but it is thought to be as follows: resorption is thought to be initiated by a combination of pressure from the permanent successor and increased masticatory forces occlusally. This is not an inflammatory process. Osteoclasts are the responsible cell for the root resorption. The clastic process ceases at the pre-dentin. Just before the tooth is exfoliated the pulp cells deposit a cementum-type substance apically and the tooth is exfoliated with potentially vital pulpal tissue (assuming the tooth was pathology free). ${ }^{139}$

\section{CONCLUSIONS}

There is now a greater understanding of the precise process involved in the pathology of resorption. It is known that certain mechanisms exist to protect teeth from the continual remodeling process that occurs within bone. These mechanisms can fail and the response can be catastrophic to dental hard tissues. The reasons that such barriers are lost may correspond to the type and location of resorptive process that follows. This can inform clinicians on the best modalities for treatment.

Thank you to Professor Horner of the University of Manchester for his time and support drafting and reviewing the legends and text pertinent to oral and maxillofacial imaging.

\footnotetext{
1. Patel $S$, Ford T P. Is the resorption external or internal? Dent Update 2007: 34: 218-229.
}

2. Fuss Z, Tsesis I, Lin S. Root resorption - diagnosis, classification and treatment choices based on stimulation factors. Dent Traumatol 2003; 19: 175-182.

3. Andreasen J 0. External root resorption: its implication in dental traumatology, paedodontics, periodontics, orthodontics and endodontics. Int Endod J 1985: 18: 109-118.

4. Calişkan $M$, Türkün $M$. Prognosis of permanent teeth with internal resorption. Endod Dent Traumatol 1997: 13: 75-81.

5. Tallat J. Artzney Buchlein. Blum, 1530

6. Fox J. The history and treatment of the diseases of the teeth, diseases of the gums and alveolar process, with the operations which they respectively require. London: James Swan, 1806.

7. Tomes J. A system of dental surgery. London: John Churchill, 1859.

8. Miller W D. A study of some dental anomalies with reference to eburnitis. Dental Cosmos 1901; 43: 845.

9. Mummery J H. The pathology of pink spots on teeth. Br Dent J 1920; 41: 301-311.

10. Boyle W J, Simonet W S, Lacey D L. Osteoclast differentiation and activation. Nature 2003; 423: 337-342.

11. Scott B L, Pease D C. Electron microscopy of the epiphyseal aparatus. Anat Rec 1956; 125: 465-495.

12. Baron R, Neff L, Brown W, Courtoy P J, Louvard $D$, Farquhar M G. Polarised secretion of lysosomal enzymes: co-distribution of cation-independent mannose-6-phosphate receptors and lysosomal enzymes along the osteoclaastic pathway. J Cell Biol 1988; 106: 1863-1872.

13. Xiong J P, Stehle T, Diefenbach B et al. Crystal structure of the extracellular segment of integrin alpha vbeta3. Science $2001 ; 294: 339-345$

14. Hynes R 0 . Integrins: versatility, modulation and signalling in cell adhesion. Cell 1992; 69: 11-25.

15. Sasaki T. Differentiation and functions of osteoclasts and odontoclasts in mineralized tissue resorption. Microsc Res Technol 2003; 61: 483-495.

16. Levin L, Trope M. Root resorption. In Hargreaves K, Goodis H (eds) Dental pulp. 3rd edn. pp 425-448. Chicago: Quintessence, 2002.

17. Yasuda H, Shima N, Nakagawa N et al. Osteoclast differentiation factor is a ligand for osteoprotegerin/osteoclastogenesis-inhibitory factor and is identical to TRANCE/RANKL. Proc Natl Acad Sci USA 1998: 95: 3597-3602.

18. Nakamura I, Takahashi N, Jimi E, Udagawa N, Suda T. Regulation of osteoclast function. Mod Rheumatol 2012; 22: 167-177.

19. Yasuda H, Shima N, Nakagawa N et al. Identity of osteoclastogenesis inhibitory factor (OCIF) and osteoprotegrin (OPG): a mechanism by which OPG/OCIF inhibits osteoclastogenesis in vitro. Endocrinology 1998; 139: 1329-1337.

20. Hofbauer L C, Khosla S, Dunstan C R, Lacey D L Boyle W J, Riggs B L. The roles of osteoprotegrin and osteoprotegrin ligand in the paracrine regulation of bone resorption. J Bone Miner Res 2000; 15: 2-12.

21. Hofbauer L C, Lacey D L, Dunstan C R, Spelsberg T C, Riggs B L, Khosla S. Interleukin-1beta and tumour necrosis factor-alpha but not interleukin-6, stimulate osteoprotegrin ligand gene expression in human osteoblastic cells. Bone 1999; 25: 255-259.

22. Stashenko P, Yu S M, Wang C Y. Kinetics of immune cell and bone resorptive responses to endodontic infections. J Endod 1992; 18: 422-426.

23. Stashenko P, Jandinski J J, Fujiyoshi P, Rynah J. Tissue levels of bone resorptive cytokines in periodontal disease. J Periodontol 1991; 62: 504-509.

24. Al-Qawasmi R A, Hartsfield J K, Everett E T et al. Genetic predisposition to external apical root resorption. Am J Orthod Dentofacial Orthop 2003: 123: 242-252.

25. Jiang Y, Mehta C K, Hsu T Y, Alsulaimani F F. Bacteria induce osteoclastogenesis via osteoblas-independent pathway. Infect Immun 2002; 70: 3143-3148.

26. Andresen J O, Andresen F M, Andersson L (eds). Textbook and colour atlas of traumatic injuries to the teeth. 4th edn. Oxford: Blackwel Munksgaard, 2006

27. Choi B K, Moon S Y, Cha J H, Kim K W, Yoo Y J. Prostaglandin $\mathrm{E}(2)$ is a main mediator in receptor 
activator of nuclear factor kappaB ligand-dependent osteoclastogenesis induced by Porphyromonas gingivalis, Treponepma denticola and Treponema sockranskii. J Periodontol 2005; 76: 813-820.

28. Yamamoto T, Kita M, Oseko F, Nakamura T, Imanish J, Kanamura N. Cytokine production in human period-ontal ligament cells stimulated with Porphyromonas gingivalis. J Periodontal Res 2006; 41: 554-559.

29. Chung $Y H$, Chang E J, Kim S J et al. Lipopolysaccharide from Prevotella nigrescens stimulates osteoclastogenesis in cocultures of bone marrow mononuclear cells and primary osteoblasts. J Periodontal Res 2006; 41: 288-296.

30. Okahashi N, Sakurai A, Nakagawa I et al. Infection by Streptococcus pyogenes induces the receptor activator of NF-kappa B ligand expression in mouse osteoblastic cells. Infect Immun 2003; 71: 948-955.

31. Nair S, Song Y, Meghji S et al. Surface-associated proteins from Staphylococcus aureus demonstrate potent bone resorbing activity. J Bone Miner Res 1995; 10: 726-734.

32. Feldman R S, Krieger N S, Tashijan A H Jr. Effects of parathyroid hormone and calcitonin on osteoclast formation in vitro. Endocrinology 1980; 107: 1137-1143.

33. Lossdörfer S, Götz W, Jäger A. Immunohistological localization of receptor activator of nuclear factor kappaB (RANK) and it's ligand (RANKL) in human deciduous teeth. Calcif Tissue Int 2002; 71: 45-52.

34. Andreasen J O, Hjorting-Hansen E. Replantation of teeth. II. Histological study of 22 replanted anterior teeth in humans. Acta Odontol Scan 1966; 24: 287-306.

35. Shaw D R, Griffin F M Jr. Phagocytosis requires repeated triggering of macrophage phagocytic receptors during particle ingestion. Nature 1981 289: 409-411.

36. Andreasen J O, Hjorting-Hansen E. Replantation of teeth. I. Radiographic and clinical study of 110 human teeth replanted after accidental loss. Acta Odontol Scand 1966; 24: 263-286.

37. Andreasen J O. Relationship between cell damage in the periodontal ligament after replantation and subsequent development of root resorption. Acta Odontol Scand 1981; 39: 15-25.

38. Andreasen J O, Kristerson L. The effect of limited drying or removal of the periodontal ligament. Acta Odontol Scand 1981; 39: 1-13.

39. Trope M. Root resorption due to dental trauma. Endodontic Topics 2002; 1: 79-100.

40. Andreasen J 0. Relationship between surface and inflammatory resorption and changes in the pulp after replantation of permanent incisors in monkeys. J Endod 1981; 7: 294-301.

41. Chambers T J. Phagocytic recognition of bone macrophages. J Pathol 1981; 135: 1-7.

42. Lindskog $S$, Pierce $A M$, Blomlof L, Hammarstrom $L$. The role of the necrotic periodontal membrane in cementum resorption and ankylosis. Endod Dent Traumatol 1985; 1: 96-101.

43. Selvig K A, Zander H A. Chemical analysis and microradiography of cementum and dentin from periodontally diseased human teeth. J Periodontol 1962: 33: 303-310.

44. Wedenberg $C_{1}$ Lindskog $S$. Evidence for a resorption inhibitor in dentin. Scand J Dent Res 1987; 95: 205-211.

45. Wedenberg C. Evidence for a dentin-derived inhibitor of macrophage spreading. Scand J Dent Res 1987; 95: 381-388

46. Haapasalo $M$, Endal U. Internal inflammatory root resorption: the unknown resorption of the tooth. Endodontic Topics 2006; 14: 60-79.

47. Claffey N, Bogle G, Bjorvatn K, Selvig K A, Egelberg $J$. Topical application of tetracycline in regernerative periodontal surgery in beagles. Acta Odonto/ Scand 1987: 45: 141-146

48. Cole R, Nilvéus $R$, Ainamo J, Bogle G, Crigger $M$, Egelberg J. Pilot clinical studies on the effect of topical citric acid application on healing after replaced periodontal flap surgery. J Periodont Res 1981; 16: 117-122.

49. Gartner A H, Mack T, Somerlott R G, Walsh L C Differential diagnosis of internal and external root resorption. J Endod 1976; 2: 329-334.

50. Cohen S, Hargreaves K. Pathways of the pulp. 9th edn Mosby, 2006.

51. Tronstad L. Root resorption - etiology, terminology and clinical manifestations. Endod Dent Traumatol 1988; 4: 241-252.

52. Feiglin B. Root resorption. Aust Dent J 1986; 31: 12-22.

53. Lindskog S, Heithersay G S, Pierce A M. Denta resorptions. In Scandinavian yearbook of dentistry. Blackwell Munksgaard, 2006.

54. Andreasen J 0. Luxation of permanent teeth due to trauma. A clinical and radiographic follow-up study of 189 injured teeth. Scand J Dent Res 1970; 78: 273-286.

55. Heithersay G S. Invasive cervical resorption. Endodontic Topics 2004; 7: 73-92.

56. Makkes P C, Thoden van Velzen S K. Cervical external root resorption. J Dent 1975; 3: 217-222.

57. Majorana A, Bardellini E, Conti G, Keller E, Pasini S. Root resorption in dental trauma: 45 cases followed for 5 years. Dent Traumatol 2003; 19: 262-265.

58. Heithersay G S. Management of tooth resorption. Aust Dent J 2007: 52(Suppl 1): 105-121.

59. Andreasen J O. A time-related study of periodontal healing and root resorption activity after replantation of permanent incisors in monkeys. Swed Dent J 1980; 4: 101-110.

60. Bergmans L, Van Cleynenbreugel J, Verbeken $E$, Wevers M, Van Meerbeek B, Lambrechts P. Cervical external root resorption in vital teeth. J Clin Periodontol 2002; 29: 580-585

61. Frank $A L$, Torabinejad M. Diagnosis and treatment of extracanal invasive resorption. J Endod 1998; 7: 500-504

62. Heithersay G S. Invasive cervical resorption: an analysis of predisposing factors. Quintessence Int 1999: 30: 83-95.

63. Kerr D. The cementum: its role in periodontal health and disease. J Periodontol 1961; 32: 183-189.

64. Liang H, Burkes E J, Frederiksen N L. Multiple idiopathic cervical root resorption: systematic review and report of four cases. Dentomaxillofac Radiol 2003: 32: 150-155.

65. Mueller E, Rony H R. Laboratory studies of an unusual case of resorption. J Am Dent Ass 1930; 17: 326-334

66. Yu VS, Messer H H, Tan K B. Multiple idiopathic cervical resorption: case report and discussion of management options. Int Endod J 2011; 44: 77-85.

67. Iwamatsu-Kobayashi Y, Sato-Kuriwada S, Yamamoto T et al. A case of multiple idiopathic external root resorption: a 6 year follow-up. Oral Surg Oral Med Oral Pathol Oral Radiol Endod 2005; 100: 772-779.

68. Macdonald-Jankowski D. Multiple idiopathic cervical root resorption most frequently seen in younger females. Evid Based Dent 2005; 6: 20

69. Neely A L, Gordon S C. A familial pattern of multiple idiopathic external resorption in a father and a son: a 22 year follow up. J Periodonto/ 2007; 78: 367-371.

70. Hammarström L, Blomlö L, Lindskog S. Dynamics of dentoalveolar ankylosis and associated root resorption. Endod Dent Traumatol 1989; 5: 163-175.

71. Hammarström L, Pierce A, Blomlöf L, Feiglin $B$ Lindskog $S$. Tooth avulsion and replantation a review. Endod Dent Traumatol 1986; 2: 1-8.

72. Andreasen J O. Analysis of pathogenesis and topography of replacement resorption. Swed Dent J 1980; 4: $231-240$

73. Andreasen J O. Periodontal healing after replantation of traumatically avulsed human teeth. Assessment by mobility testing and radiography. Acta Odontol Scand 1975; 33: 325-335.

74. Andreasen $\mathrm{J} 0$. The effect of splinting upon periodontal healing after replantation of permanent incisors in monkeys. Acta Odonto/ Scand 1975; 33: 313-323.

75. Andersson L, Bodin I, Sörensen S. Progression of root resorption following replantation of human teeth after extended extraoral storage. Endod Dent Traumatol 1989; 5: 38-47.

76. Barrett E J, Kenny D J. Survival of avulsed permanent maxillary incisors in children following delayed replantation. Endod Dent Traumatol 1997.
13: 269-275.

77. Vier FV, Figueiredo J A. Internal apical resorption and its correlation with the type of apical lesion. Int Endod J 2004; 37: 730-737.

78. Andreasen J O, Andreasen F M. Root resorption following traumatic dental injuries. Proc Finn Dent Soc 1992; 88(Suppl 1): 95-114.

79. Goultschin J, Nitzan D, Azaz B. Root resorption. Review and discussion. Oral Surg Oral Med Oral Pathol 1982; 54: 586-590.

80. Wedenberg C, Zetterqvist L. Internal resorption in human teeth - a histological, scanning electron microscopic, and enzyme histochemical study. J Endod 1987: 13: 255-259.

81. Patel S, Ricucci D, Durak C, Tay F. Internal root resorption: a review. J Endod 2010; 36: 1107-1121.

82. Wedenberg $C_{1}$ Lindskog $S$. Experimental internal resorption in monkey teeth. Dent Traumatol 1980; 1: 221-227.

83. Wedenberg C. Development and morphology of internal resorption in teeth - a study in humans, monkeys and rats. Stockholm: Kongl Carolinska Medico Chirurgiska Institutet, 1987.

84. Trope M. Root resorption of dental and traumatic origin: classification based on etiology. Pract Periodont Aesthet Dent 1998; 10: 515-522.

85. Heithersay G S. Clinical endodontic and surgical management of tooth and associated bone resorption. Int Endod J 1985; 18: 72-92.

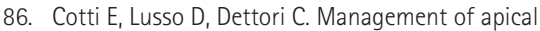
inflammatory root resorption: report of a case. Int Endod J 1998; 31: 301-304.

87. Lau Y S, Wang W, Sabokbar A et al. Staphylococcus aureus capsular material promotes osteoclast formation. Injury 2006; 37(Suppl 2): 41-48.

88. Laux M, Abbott PV, Pajarola G, Nair P N. Apical inflammatory root resorption: a correlative radiographic and histological assessment. Int Endod J 2000; 33: 483-493.

89. Brice G L, Sampson W J, Sims M R. An ultrastructural evaluation of the relationship between epithelial rests of Malassez and orthodontic root resorption and repair in man. Aust Orthod J 1991 12: 90-94.

90. Palmer R, Floyd P D. A clinical guide to peridontology. 2nd edn. London: British Dental Association, 2003.

91. Magnusson I, Claffey N, Bogle G, Garrett S, Egelberg J. Root resorption following periodontai flap procedures in monkeys. J Periodontal Res 1985; 20: 79-85.

92. Karring T, Nyman S, Lindhe J, Sirirat M. Potentials for root resorption during periodontal wound healing. J Clin Periodontol 1984; 11: 41-52.

93. Beertsen $W$, Piscaer $M$, Van Winklehoff $A J$, Everts $V$ Generalized cervical root resorption associated with periodontal disease. J Clin Periodontol 2001; 28: 1067-1073.

94. Andreasen J 0. The effect of extra alveolar period and storage media upon periodontal and pulpal healing after replantation of mature permanent incisors in monkeys. Int J Oral Surg 1981; 10: 43-53.

95. Söder P O, Otteskog P, Andreasen J O, Modéer T. Effect of drying on viability of periodontal memebrane. Scand J Dent Res 1977; 85: 164-168.

96. Blomlöf L, Andersson L, Lindskog S, Hedström K G, Hammarström L. Periodontal healing of replanted teeth prevented from drying. Acta Odonto/ Scand 1983; 41: 117-123.

97. Lindskog S, Blomlöf L, Hammarström L. Cellular colonization of denuded root surfaces in vivo. J Clin Periodontal 1987: 14: 390-395.

98. Mattison G D, Delivanis H P, Delivanis P D, Johns P I. Orthodontic root resorption of vital and endodontically treated teeth. J Endod 1984; 10: 354-358.

99. Cwyk F, Saint-Pierre F, Tronstad L. Endodontic implications of orthodontic movement. J Dent Res 1984: 63: 286

100. Zachrisson B U. Cause and prevention of injuries to teeth and supporting structures during orthodontic treatment. Am J Orthod 1976; 69: 285-300.

101. Sjolien T, Zachrisson B U. Periodontal bone support and tooth length in orthodontically treated and untreated patients. Am. J Orthod 1973; 64: 28-37.

102. Linge L, Linge B O. Patient characteristics and 
treatment variables associated with apical root resorption during orthodontic treatment. Am J Orthod Dentofacial Orthop 1991; 99: 35-43.

103. Segal G R, Schiffman P H, Tuncay O C. Meta analysis of the treatment-related factors of external apical root resorption. Orthod Craniofac Res 2004; 7: 71-78.

104. Mirabella A D, Artun J. Prevalence and severity of apical root resorption of maxillary anterior teeth in adult orthodontic patients. Euro J Orthod 1995. 17: 93-99.

105. Bender I B, Byers M R, Mori K. Periapical replacement resorption of permanent, vital, endodontically treated incisors after orthodontic movement: report of two cases. J Endod 1997; 23: 768-773.

106. Sailus J, Trowbridge H, Greco M, Emling R. Sensitivity of teeth subjected to orthodontic forces. J Dent Res 1987; 66: 556

107. Kurol J, Owman-Moll P. Hyalinization and root resorption during early orthodontic tooth movement in adolescents. Angle Orthod 1998; 68: 161-165.

108. Brezniak N, Wasserstein A. Orthodontically induced inflammatory root resorption. Part I: the basic science aspects. Angle Orthod 2002; 72: 175-179.

109. Yamaguchi M, Aihara N, Kojima T, Kasai K. RANKL increase in compressed periodontal ligament cells from root resorption. J Dent Res 2006 ; 85: 751-756.

110. Brudvik P, Rygh P. Root resorption beneath the main hyalinized zone Eur J Orthod 1994 16: 249-263.

111. Brudvik P, Rygh P. Transition and determinants of orthodontic root resorption-repair sequence. Eur Orthod 1995; 17: 177-188.

112. Hines F B Jr. A radiographic evaluation of the response of previously avulsed teeth and partially avulsed teeth to orthodontic movement. Am J Orthod 1979; 75: 1-19.

113. Newman W G. Possible etiological factors in external root resorption. Am J Orthod 1975; 67: 522-539.

114. Chu F C, Li T K, Lui V K, Newsome P R, Chow R L, Cheung $L K$. Prevalence of impacted teeth and associated pathologies - a radiographic study of the Hong Kong Chinese population. Hong Kong Med J 2003; 9: 158-163.

115. Nitzan D, Keren T, Marmary Y. Does and impacted tooth cause root resorption of the adjacent one? Oral Surg Oral Med Oral Pathol 1981; 51: 221-224.

116. Henefer E P. Root resorption by an impacted tooth Oral Surg Oral Med Oral Pathol 1968; 26: 658.

117. Ericson S, Kurol J. Radiographic examintion of ectopically erupting maxillary canines. Am J Orthod Dentofacial Orthop 1987; 91: 483-492.

118. Walker L, Enciso R, Mah J. Three-dimensional localization of maxillary canines with cone-beam computed tomography. Am J Orthod Dentofacial Orthop 2005: 128: 418-423.

119. Gunst $V$, Huybrechts $B$, De Almeida Neves $A$, Bergmans L, Van Meerbeek B, Lambrechts P. Playing wind instruments as a potential aetiological cofactor in external cervical resorption: two case reports. Int Endod J 2011; 44: 268-282.

120. Eriksson A R, Albrektsson T. Temperature threshold levels for heat-induced bone tissue injury: a vitalmicroscopic study in the rabbit. J Prosthetic Dent 1983; 50: 101-107.

121. Saunders E M. In vivo findings findings associated with heat generation during thermomechanical compaction of gutta-percha. 2. Histological response to temperature elevation of the external surface of the root. Int Endod J 1990; 23: 268-274.

122. Zhang L, Zhou X, Wang O, Wang Y, Tang L, Huang D. Effect of heat stress on the expression levels of receptor activator of NF-KB ligand and osteoprotegrin in human periodontal ligament cells. Int Endod J 2012; 45: 68-75.

123. Floren J W, Weller R N, Pashley D H, Kimbrough W F. Changes in root surface temperatures with in vitro use of the system B heat source. J Endod 1999; 25: 593-595.

124. Harrington G W, Natkin E. External resorption associated with bleaching of pulpless teeth. J Endod 1979; 5: 344-348.

125. Cvek M, Lindvall A. External root resorption following bleaching of pulpless teeth with oxygen peroxide. Endod Dent Traumatol 1985; 1: 56-60.

126. Mjor I A, Pindborg J J. Histology of the human tooth. Munksgaard, Scandinavian University Books, 1973.

127. Friedman S, Rotstein I, Libfeld H, Stabholz A, Heling I. Incidence of external root resorption and esthetic results in 58 bleached pulpless teeth. Endod Dent Traumatol 1988; 4: 23-26.

128. Lado E A, Stanley H R, Weisman M. Cervical resorption in bleached teeth. Oral Surg Oral Med Oral Pathol 1983; 55: 78-80.

129. McCormick J E, Weine FS, Maggio J D. Tissue pH of developing periapical lesions in dogs. J Endod 1983; 9: 47-51.

130. Zhang J, Kashket S. Cytotoxic effects of short-chain carboxylic acids on human gingival epithelial cells. Oral Microbiol Immunol 1997; 12: 345-349.

131. Patel $S$, Kanagasingam S, Pitt Ford T. External cervical resorption: a review. J Endod 2009; 35: 616-625.

132. Heithersay G S, Dahlstrom S W, Marin P D. Incidence of invasive cervical resorption in bleached root-filled teeth. Aust Dent J 1994; 39: 82-87.

133. van Wessum R, Harvey C $E_{1}$ Hennet P. Feline dental resorptive lesions: prevalence patterns. Vet Clin North Am Small Anim Pract 1992; 22: 1405-1416.

134. Berger $M$, Schawalder $P$, Stich $H$, Lussi A. Feline dental resorptive lesions in captive and wild leopards and lions. J Vet Dent 1996; 13: 13-21.

135. von Arx T, Schawalder P, Ackermann M, Bosshardt D D. Human and feline invasive cervical resorptions: the missing link? - Presentation of four cases. J Endod 2009; 35: 904-913.

136. Soloman C S, Coffiner M O, Chaflin H E. Herpes zoster revisited: implicated in root resorption. J Endod 1986; 12: 210-213.

137. Ramchandani P L, Mellor T K. Herpes zoster associated with tooth resorption and periapical lesions. Br J Oral and Maxillofac Surg 2007; 45: 71-73.

138. Engström C, Granström G, Thilander B. Effect of orthodontic force on periodontal tissue metabolism. A histologic and biochemical study in normal and hypocalcaemic young rats. Am J Orthod Dentofacial Orthop 1988; 93: 486-495.

139. Ten Cate A. Oral histology: development, structure and function. 5th edn. St Louis: C V Mobsy, 1998 